\title{
Nanomedicines for dysfunctional macrophage-associated diseases
}

\author{
Hongliang $\mathrm{He}^{1}$, Shobha Ghosh ${ }^{2 *}$ and Hu Yang ${ }^{1,3,4 *}$ \\ ${ }^{1}$ Department of Chemical and Life Science Engineering, Virginia Commonwealth University, Richmond, \\ Virginia 23219, United States \\ ${ }^{2}$ Department of Internal Medicine, Virginia Commonwealth University, Richmond, Virginia 23298, \\ United States \\ ${ }^{3}$ Department of Pharmaceutics, Virginia Commonwealth University, Richmond, Virginia 23298, United \\ States \\ ${ }^{4}$ Massey Cancer Center, Virginia Commonwealth University, Richmond, Virginia 23298, United States
}

${ }^{*}$ Corresponding author

E-mail address: hyang2@vcu.edu

E-mail address: shobha@vcu.edu

(C) 2016. This manuscript version is made available under the Elsevier user license

http://www.elsevier.com/open-access/userlicense/1.0/ 

Abstract
1Introduction
2Nanomedicines and approaches for homing to macrophage
3 Nanomedicines targeting dysfunctional macrophage in diseases
3.1 Dysfunctional macrophages in cancer
3.2 Dysfunctional macrophages in atherosclerosis
3.3 Dysfunctional macrophages in rheumatoid arthritis (RA)
3.4 Dysfunctional macrophages in inflammatory bowel disease (IBD)
3.5 Dysfunctional macrophages in obesity and ensuing insulin resistance for type 2 diabetes
3.6 Dysfunctional macrophages in HIV/AIDS
4 Concluding remarks and future perspectives
Reference

Figures 


\begin{abstract}
Dysfunctional macrophageshave significantpathophysiological roles in diseases, including malignant tumors, inflammatory diseases (rheumatoid arthritis and inflammatory bowel disease), metabolic diseases (atherosclerosis, diabetes and obesity) and major infections like HIV/AIDS.Developing nanomedicines to target dysfunctional macrophages within diseases' foci is a promising approach to treating those diseases with better outcomes. This review discussesthe roles dysfunctional macrophages have in cancerous, metabolic and infectious diseases and reviews the latest advances on nanomedicines-based therapies fortreating diseasesassociated with dysfunctional macrophages.
\end{abstract}

Keywords:dysfunctional macrophages; nanomedicines; cancer; atherosclerosis; RA; IBD; obesity; diabetes; HIV 


\section{Introduction}

Macrophages originatefrom the differentiation of blood-derived monocytes and mainly residewithin tissues throughout the body. Macrophages respond to alterations in their microenvironment by producing a wide variety of products to mediate inflammation, tissue injury, homeostasis and immunity[1, 2]. Granulocyte/monocyte precursor cells develop into monocytes induced byendogenousstimulisuch asmacrophage colony-stimulating factor (M-CSF), granulocyte-macrophage colony stimulating factor (GM-CSF) and interleukin-3 (IL-3). De novo monocytes leave the bone marrow, enter the bloodstream and approximately one day later migrate into tissues where they differentiate into tissue macrophages(called resident macrophages). They have different names based on their locations such askupffer cells in the liver, alveolar macrophages in lungs, red pulp macrophages in spleen, and sinus histiocytes in lymph nodes[2, 3].Although those tissue macrophages are anatomically distinct from one another and have diversefunctional capabilities and transcriptional features, they are invariablyessentialin maintainingthe physiological function and homeostasis of organism (Fig. 1)[2, 4].

When some parts in our body (like tissues) get damaged as a result of infection or injury, circulating blood monocytes are recruited from the circulation and differentiate into macrophages once they migrate into the affected tissues[1, 5]. Macrophagescan recognize pathogen-associated moleculesand apoptotic cells-associatedendogenous ligands through receptor-mediatedrecognition patterns. Those recognition eventsare generally endedwith pathogen clearance by phagocytosis and consequent infection alleviation.However, when macrophages are inappropriately activated,an uncontrollable inflammatory response would be initiated, andtheir homeostatic and reparativefunctions would be subverted, thus resulting in a causal association of macrophages with disease states[6, 7], including growth and metastasis of malignant tumors[8-10], inflammatory diseases (rheumatoid arthritis[11-14] and inflammatory bowel disease[15, 16]), metabolic diseases (atherosclerosis[17-19], 
diabetes[20-22] and obesity[23, 24]) and severe infections like HIV/AIDS[25, 26]. Therefore, based on their pathophysiological roles in diseases,targeting the recruitment, activation and regulation of dysfunctional macrophages within those diseases' foci have emerged as a promising therapeutic strategy[5, 7, 27]. Although many molecular-base therapies have been developed to target dysfunctional macrophages to restore their protection functions, the lack ofmacrophage-specific targeting greatly restricts the application of treatments with minimizedadverse side-effects[27, 28]. Emergence and advancementof nanotechnology have given rise to specific targeting nanomedicines, and opened upnew opportunities for treating diseasesassociated with dysfunctional macrophages[27-31]. This review discusses how macrophages play roles in various pathophysiological diseasesandreviewshow nanomedicines are utilized to treat dysfunctional macrophage-associated diseases.

\section{Nanomedicinesand approaches for homing to macrophages}

Nanomedicines, the application of nanotechnology to medicine, is highly anticipated to help us solve a number of concerns associated with conventional therapeutic agents, including poor water solubility (for most new molecule entity), lack of targeting specificity, nonspecific distribution, systemic toxicity, and low therapeutic index[31-33]. Over the past several decades, remarkable progress has been achieved in the development and application of engineered nanoparticles to treat various diseases[34]. Themost popularengineered nanoparticles (Fig. 2)includepolymeric nanospheres, lipid structured carriers (liposomes and emulsions), polymeric micelles, dendrimers, inorganic nanoparticles (mesoporous silica nanoparticle,gold nanoparticles, quantum dots and carbon nanotubes)[35-37]. Additionally, the different types of nanoparticles with focus on material, cargo attachment, and their various advantages and disadvantages aresummarizedin Table 1. 


\section{Table 1 Summary of different types of engineerednanoparticles}

\begin{tabular}{|c|c|c|c|c|c|c|}
\hline Types & $\begin{array}{l}\text { Size } \\
(\mathrm{nm})\end{array}$ & Compositions & Cargo loading manner & Advantages & Disadvantages & Ref. \\
\hline Nanospheres & $10-1000$ & $\begin{array}{l}\text { Solid hydrophobic } \\
\text { nanoparticlesbased on } \\
\text { polymer matrix }\end{array}$ & $\begin{array}{l}\text { Embedded in the } \\
\text { polymer matrix or } \\
\text { loaded within the core }\end{array}$ & $\begin{array}{l}\text { High loading capacity } \\
\text { andcontrollable release }\end{array}$ & $\begin{array}{l}\text { Difficult to purify and } \\
\text { poor stability }\end{array}$ & {$[38,39]$} \\
\hline Liposomes & $\begin{array}{l}100- \\
1000\end{array}$ & $\begin{array}{l}\text { Self-assembly oflipid } \\
\text { bilayer }\end{array}$ & $\begin{array}{l}\text { Encapsulated within } \\
\text { the hydrophilic core and } \\
\text { hydrophobicbilayer }\end{array}$ & $\begin{array}{l}\text { Easily fabrication, } \\
\text { better biocompatible and } \\
\text { suitable for both hydrophobic } \\
\text { and hydrophilic drug loading }\end{array}$ & $\begin{array}{l}\text { Stability issues like } \\
\text { cohesion and drug leakage }\end{array}$ & [40-42] \\
\hline Emulsions & $\begin{array}{l}100- \\
1000\end{array}$ & $\begin{array}{l}\text { Amphipathicsurfactant } \\
\text { embedding inner } \\
\text { hydrophobic core }\end{array}$ & $\begin{array}{l}\text { Encapsulated within the } \\
\text { hydrophobic core }\end{array}$ & $\begin{array}{l}\text { Highly hydrophobic } \\
\text { drug loading }\end{array}$ & $\begin{array}{l}\text { Stability issue like } \\
\text { flocculation, coalescence } \\
\text { and aggregation }\end{array}$ & {$[43,44]$} \\
\hline Micelles & $10-100$ & $\begin{array}{l}\text { Hydrophobic core } \\
\text { surroundedby } \\
\text { amphipathicpolymer }\end{array}$ & $\begin{array}{l}\text { Encapsulated within } \\
\text { the hydrophobic core }\end{array}$ & $\begin{array}{l}\text { Small size and } \\
\text { able to incorporate highly } \\
\text { hydrophobic cargo }\end{array}$ & $\begin{array}{l}\text { Highly sensitive to } \\
\text { structuralchanges } \\
\text { below CMC and } \\
\text { poor release profiles }\end{array}$ & {$[45,46]$} \\
\hline Dendrimers & $10-100$ & $\begin{array}{l}\text { Highly and uniformly } \\
\text { branched polymer }\end{array}$ & $\begin{array}{l}\text { Embedded inside the } \\
\text { branches, conjugated to } \\
\text { the surface chemical } \\
\text { group,or electronic } \\
\text { complexwithgene/siRN } \\
\text { A }\end{array}$ & $\begin{array}{l}\text { Highly water } \\
\text { solubleandfunctionalized } \\
\text { surface groups. }\end{array}$ & $\begin{array}{l}\text { Concerns about toxicity } \\
\text { from highly positive } \\
\text { surface charge and } \\
\text { biocompatibility }\end{array}$ & [47-49] \\
\hline $\begin{array}{l}\text { Mesoporous } \\
\text { silica } \\
\text { nanoparticles }\end{array}$ & $20-200$ & $\begin{array}{l}\text { Mesoporous form of } \\
\text { silica with nanosize }\end{array}$ & $\begin{array}{l}\text { Encapsulated within } \\
\text { the mesopores by } \\
\text { hydrophobic interaction }\end{array}$ & $\begin{array}{l}\text { High loading capacity, } \\
\text { andhomogenous distribution } \\
\text { for guest molecules into } \\
\text { porous }\end{array}$ & $\begin{array}{l}\text { Low drug release; lack of } \\
\text { in vivostudies on PK/PD, } \\
\text { bio-distribution and } \\
\text { clearance }\end{array}$ & {$[50,51]$} \\
\hline $\begin{array}{l}\text { Gold } \\
\text { nanoparticles }\end{array}$ & $2-100$ & $\begin{array}{l}\text { Solid gold particles } \\
\text { within nanometer }\end{array}$ & $\begin{array}{l}\text { Attached to the } \\
\text { surface/surface coating }\end{array}$ & $\begin{array}{l}\text { Innate optical and } \\
\text { photothermal properties }\end{array}$ & $\begin{array}{l}\text { No inner loading cavity; } \\
\text { poor biocompatibility and } \\
\text { biodegradability. }\end{array}$ & [52-54] \\
\hline Quantum dots & $2-10$ & $\begin{array}{l}\text { Typically cadmium } \\
\text { selenide core with } \\
\text { a zinc selenide cap }\end{array}$ & $\begin{array}{l}\text { Attached to the surface } \\
\text { or surface coating }\end{array}$ & $\begin{array}{l}\text { Innate optical properties and } \\
\text { highextinction coefficient. }\end{array}$ & $\begin{array}{l}\text { No inner loading cavity } \\
\text { and toxicity issues }\end{array}$ & {$[55,56]$} \\
\hline $\begin{array}{l}\text { Carbon } \\
\text { nanotubes }\end{array}$ & $\begin{array}{l}1-5 \\
\text { diameter } \\
1-150 \\
\text { length }\end{array}$ & $\begin{array}{l}\text { Graphite arranged in } \\
\text { either a sheet } \\
\text { or cylindrical structure }\end{array}$ & $\begin{array}{l}\text { Entrapped insidethe } \\
\text { carbon backbone }\end{array}$ & $\begin{array}{l}\text { Innate optical and electrical } \\
\text { properties, and high surface } \\
\text { drug loading }\end{array}$ & $\begin{array}{l}\text { Expensive production, } \\
\text { poor biodegradability and } \\
\text { organ accumulation }\end{array}$ & {$[57,58]$} \\
\hline
\end{tabular}

In comparison to traditional formulations, nanoparticle-based nanomedicines offer many distinctivecharacteristics, including: 1) improved delivery of drugs with poorly water solubility; 2) extended plasma half-life of the drug in the systemiccirculation throughbetter protection of the drug from harsh environments in physiological conditions (such ashigh levels of proteases or other types of enzymes in the blood stream and the highly acidic environment in the stomach or the lysosomes of a cell) before they can reach the targets; 3) controlled drug release over a manageable period of time at precise doses; 4) co-delivery of multiple types of drugs and/or diagnostic agents (like contrast/imagingagents) for combination therapy and real-time readout on the treatment efficacy; and 5) targeted drugdelivery in 
a cell-specific or tissue-specific manner so that the treatment efficacy can be maximized while systemic side effects are minimized[32, 35]. These advantages have already made several excellent nanomedicinesavailable on market orin clinic trials[34, 36, 59, 60], and alsocan be utilized to provide better therapeutic solutions to diseases arising from dysfunctional macrophages.

To further enhance the specificity to those dysfunctional macrophages in diseases' foci, active targeting approaches can be achieved based on the surface modification of the nanoparticles with moieties (such as ligand, antibody and peptide, etc.) that have selective affinity for recognizing and interacting with certain receptors on the surface of macrophages[28, 31, 61-64]. Table 2 briefly describes some receptorsthat are overexpressed on the surface of macrophages and have been utilizedfor actively targeting macrophages, including mannose receptor,scavenger receptors,dectin-1 receptor,tuftsin peptide, CD44 receptor, folate receptor beta (FR-b) andphosphatidylserine receptor.

Table2 Examples of receptors targeting macrophages

\begin{tabular}{|c|c|c|}
\hline $\begin{array}{l}\text { Macrophage-targeted } \\
\text { receptors }\end{array}$ & Brief description & Ref. \\
\hline Mannose receptor & $\begin{array}{l}\text { Cluster of Differentiation 206, CD206; } \\
\text { A C-type lectin primarily present on the surface of macrophages can recognize } \\
\text { mannose terminal, N-acetylglucosamine and fucose residuesmolecules with high } \\
\text { affinity. }\end{array}$ & [65-68] \\
\hline Scavenger receptor & $\begin{array}{l}\text { A group of receptors (categorized into classes A, B, and C) that highly recognize } \\
\text { modified low-density lipoprotein (LDL) such as SR-A and CD36. }\end{array}$ & [69-73] \\
\hline Dectin-1 receptor & $\begin{array}{l}\text { A non-opsonic b-glucan receptor, overexpressed inmacrophages, is essential for the } \\
\text { phagocytosis of yeast bymacrophages through the recognition of b-glucans, a } \\
\text { cellularcomponent of yeast. }\end{array}$ & {$[74-76]$} \\
\hline Tuftsin peptide & $\begin{array}{l}\text { Tetra-peptide sequence l-Thr-l-Lys-l-Pro-l-Arg (TKPR); } \\
\text { Synthesized by the enzymatic processing ofthe Fc fragment of the heavy chain of } \\
\text { IgG molecule; } \\
\text { Activates macrophage and enhances their phagocytic ability. }\end{array}$ & {$[77-79]$} \\
\hline CD44 receptor & $\begin{array}{l}\text { Cell-surface glycoprotein involved in cell-cell interactions, cell adhesion and } \\
\text { migration; } \\
\text { Distinctive receptor for hyaluronic acid and can also interact with other ligands, } \\
\text { such as osteopontin, collagens, and matrix metalloproteinases (MMPs). }\end{array}$ & {$[80-82]$} \\
\hline $\begin{array}{l}\text { Folate receptor } \\
\text { beta(FR-b) }\end{array}$ & $\begin{array}{l}\text { FR-bis specifically expressed by activated macrophages and shows a high affinity } \\
\text { for folic acid (FA). }\end{array}$ & [83-86] \\
\hline $\begin{array}{l}\text { Phosphatidylserine } \\
\text { receptor }\end{array}$ & $\begin{array}{l}\text { Responsible for clearance of apoptotic cells overexpressing phosphatidylserine on } \\
\text { the outleft of membrane. }\end{array}$ & {$[87,88]$} \\
\hline
\end{tabular}

\section{Nanomedicines targeting dysfunctional macrophage-associated diseases}


Dysfunctional macrophages havecommon pathological features and critical implicationsin the pathogenesis of many disorder conditions ofvarious diseases, and thereforedysfunctional macrophage could serve as a potential target for the prevention and treatment of these diseases. We highlight the characteristics and some potential therapeutic strategies of dysfunctional macrophage-associated diseases(Fig.3 and Table 3), along with some selected examplesfromrecently reported nanomedicinebased therapies[1, 5, 7]. 


\section{Table 3 Overview of major dysfunctional macrophage-associateddiseases and selected nanomedicines}

\begin{tabular}{|c|c|c|c|}
\hline Disease type & $\begin{array}{l}\text { Involvement of dysfunctional } \\
\text { macrophage }\end{array}$ & $\begin{array}{l}\text { Potential therapeutic strategies for } \\
\text { dysfunctional macrophage }\end{array}$ & $\begin{array}{l}\text { Selected nanomedicines } \\
\text { based on dysfunctional } \\
\text { macrophage }\end{array}$ \\
\hline Cancer & $\begin{array}{l}\text { Macrophage within the } \\
\text { tumormicroenvironment, termed as tumor } \\
\text { associated macrophages } \\
\text { (TAMs),facilitate angiogenesis, } \\
\text { extracellular matrix remodelingand } \\
\text { promote tumor cell metastasis. }\end{array}$ & $\begin{array}{l}\text { Inhibiting macrophage recruitment } \\
\text { and activation; } \\
\text { Suppressing TAMs survival; } \\
\text { Enhancing M1-like tumoricidal } \\
\text { activity of TAMs and blocking M2- } \\
\text { like tumor-promoting activity of } \\
\text { TAMs. }\end{array}$ & [89-93] \\
\hline $\begin{array}{l}\text { Rheumatoid } \\
\text { arthritis }\end{array}$ & $\begin{array}{l}\text { The abundance and activation of } \\
\text { macrophages in the inflamed synovial } \\
\text { membrane/pannus lead to inflammation } \\
\text { and ensuing osteoclasts. }\end{array}$ & $\begin{array}{l}\text { Reduce the numbers of activated } \\
\text { macrophages to inhibit activation } \\
\text { signals and/or their } \\
\text { specificproducts that amplify the } \\
\text { disease. }\end{array}$ & [94-97] \\
\hline $\begin{array}{l}\text { Inflammatory } \\
\text { bowel disease }\end{array}$ & $\begin{array}{l}\text { A change in flora or a defect in } \\
\text { microbialclearing processes can lead to } \\
\text { uncontrolledmicrobial growth in the } \\
\text { lamina propria, thusstimulating } \\
\text { recruitment and activation of } \\
\text { inflammatory macrophages }\end{array}$ & $\begin{array}{l}\text { Use of receptor agonists or } \\
\text { antagonists that stimulate intestinal } \\
\text { immune responses to achieve the } \\
\text { required response, thus inhibiting } \\
\text { the recruitment of macrophage } \\
\text { from blood. }\end{array}$ & [98-101] \\
\hline Atherosclerosis & $\begin{array}{l}\text { Under stimulus from oxLDL,the } \\
\text { recruited monocyte differentiates into } \\
\text { macrophages that overexpress scavenger } \\
\text { receptors, which internalize } \\
\text { excessiveoxLDL in an unregulated } \\
\text { manner, thus propagating the } \\
\text { inflammatory cascade and leading to neo- } \\
\text { intimal plaques }\end{array}$ & $\begin{array}{l}\text { Alleviate the inflammation in } \\
\text { intima to stop the monocyte } \\
\text { recruitment; } \\
\text { Inhibit lipid accumulation in } \\
\text { macrophage to stop the foam cell } \\
\text { formation; } \\
\text { Enhance the removal of cholesterol } \\
\text { ester from the existing plaque. }\end{array}$ & [102-106] \\
\hline Diabetes & $\begin{array}{l}\text { Pro-inflammatory cytokines produced by } \\
\text { M1-like macrophages abundant in } \\
\text { adipose tissue inhibit insulin receptor } \\
\text { signaling and lead to insulin resistance. }\end{array}$ & $\begin{array}{l}\text { Anti-inflammatory treatments; } \\
\text { Transition in macrophage } \\
\text { polarization from M1-like state } \\
\text { back to M2-like state }\end{array}$ & [107-109] \\
\hline Obesity & $\begin{array}{l}\text { Adipose tissue is intimately characterized } \\
\text { by infiltration of large number of pro- } \\
\text { inflammatory macrophages ( termed as } \\
\text { adipose tissue macrophages, ATMs) }\end{array}$ & $\begin{array}{l}\text { Anti-inflammatory treatments; } \\
\text { Transition in macrophage } \\
\text { polarization from M1-like state } \\
\text { back to M2-like state }\end{array}$ & [110-113] \\
\hline HIV/AIDS & $\begin{array}{l}\text { Macrophages not only act as the HIV } \\
\text { antigen presenting cells and also } \\
\text { disseminate HIV-1 rival throughout the } \\
\text { body }\end{array}$ & $\begin{array}{l}\text { Targeting HIV-1 reservoir in } \\
\text { macrophages; } \\
\text { Sensitive the antigen presenting } \\
\text { capacity for macrophage; }\end{array}$ & [114-117] \\
\hline
\end{tabular}

\subsection{Dysfunctional macrophages in cancer}

\subsubsection{Involvement of tumor-associated macrophages in cancer development}

Accumulating evidences from clinical and experimental studies indicate thatmacrophagesin tumor tissues, namely tumor-associated macrophages (TAMs), have important roles in progression and 
metastasis of solidtumors[118-120]. TAMs are the main population ofinflammatory cells in solid tumors and the cytokinesreleased from them possess diversified roles intumor advancement.Specifically, macrophages are first derived from blood-derived monocyte,activatedby some chemotactic factors within tumor microenvironmentand then actively provide many trophic functions that facilitate tumor progression and metastasis. Many studies havealready demonstrated that the majority of TAMs are activated M2-likemacrophages, with anti-inflammatory properties that very differ from the proinflammatory M1-likemacrophages which are usually resident in tissue areaswith acute inflammation. Once being activated, M2-like TAMshighly express amount of tumor-promoting cytokines and growth factors (such as endothelial growth factor, angiopoietin, matrix metalloproteinase 9 and TNF- $\alpha$, etc.), and thus facilitate tumor promotion, angiogenesis,progression and metastasis, matrix remodeling and immune evasion (Fig. 4). Additionally experimentalinvestigations indicate that TAMsalso contribute to drug-resistanceand radioactivity-protective effects, and clinical evidences show that an elevatednumber of TAMs and their M2-like profile are positivelycorrelated with poor prognosis and therapeutic failurein cancer patients[91, 121].Therefore specific TAMs-targeted drug delivery, depletion of TAMsandconversionfromtumor-promoting M2 subtype to tumor-suppressing M1 subtype have now been considered as potential targets for adjuvant anti-cancer therapy.

\subsubsection{Tumor-associated macrophages as a therapeutic target for cancer treatment}

Recently, TAMs-targetedstrategies have achieved significant progress and some worksgot encouraging results.Based on the proposed involvement of TAMs in tumor,those strategies are generally classified into the four categories: (1) inhibitingrecruitment and activationof monocyte-derived macrophage[122]; (2) repressing surviveof TAMs[123]; (3) enhancingthe anti-tumor activity of M1-like TAMs[74]; (4) suppressingthe tumor-promotingactivity of M2-like TAMs[124-126]. 
Although the clinical applicationof molecular-based TAMtargeting approach is still far from success, anumber of experimental studies have collectively shownthe utility of this approach on effective tumor suppression andwell therapeutic outcomes, which sheds inspirationallight on further clinical trials.Several excellent reviews[118, 119, 124-127] have been written on targeting tumorassociated macrophagesin cancer therapy, but with a fewfocuses on the field ofnanomedicines targeting TAMs.So herewe aim to brieflyreview with particular emphasis on recentdevelopments and applications ofTAMs-targeting nanomedicines for anticancer therapy.

Sinceunlike the tumor-promoting M2-like macrophage, the pro-inflammatory M1-like macrophages in the tumor exert anti-proliferative and cytotoxic activities against the progression of tumor, which is due to their ability to secrete oxygen species andreactive nitrogen (such as hydrogen peroxide, NO, peroxynitrite, and superoxide, etc.) and some pro-inflammatory cytokines (such as TNF- $\alpha$, IL-1, and IL-6)[128-130].Hence, reprograming the TAMs from M2-like subtype to M1-like subtype could be an efficient strategy for anticancer therapy. Song et al. developedmannan-conjugated $\mathrm{MnO}_{2}$ particle with hyaluronic acid (HA) modification (Man-HA-MnO $2 \mathrm{NPs}$ ), where mannan was utilized as a macrophage targeted ligand, $\mathrm{MnO}_{2}$ was used as tumor hypoxia alleviator by highly reacting with hydrogen peroxide in tumorous hypoxic area for simultaneous production of $\mathrm{O}_{2}$ and regulation of $\mathrm{pH}$ and HA modification was to reprogram anti-inflammatory, pro-tumoral M2 TAMs to pro-inflammatory, antitumor M1 macrophages to further enhance the ability of $\mathrm{MnO}_{2} \mathrm{NPs}$ to lessen tumor hypoxia and also modulate chemoresistance (Fig 5).The results showed that this multifunctional nanoparticle significantly increased tumor oxygenation and M1-like population in tumor. Combination treatment of the tumors with Man-HA- $\mathrm{MnO}_{2}$ NPs and doxorubicin significantly inhibited tumor growth in comparison tofree doxorubicin alone. Besides, the ability of Man-HA- $\mathrm{MnO}_{2}$ NPs to react with endogenous $\mathrm{H}_{2} \mathrm{O}_{2}$ highly enhanced T1- and T2-MRI performance for better tumor imaging application [131]. 
In order to actively targeted delivery of anticancer agents to the TAMs but reduce the nonspecific uptakebysome normal organs, Zhu et al. reported a PEG-sheddable and mannose-modified nanoparticle that efficiently targetedTAMs via mannose receptor after shedding acid-sensitive PEG coating in the acidic tumor microenvironment, while reduced the unwanted uptake by normal macrophages in the mononuclear phagocyte system (MPS) organs due to effective PEG shielding at neutral $\mathrm{pH}$ condition. Animal studies showedthis novel modified-nanoparticlepossessed higher tumor accumulation but lower undesired normal tissues accumulation than the unmodified one, likely due to smartPEGylation shielding/shedding and mannose modification [132]. Niu et al. also demonstratedcombination of mannose modification and acid-sensitive sheddable PEGylation TAMshighly delivered doxorubicin (DOX) to TAMs in triple-negative breast cancer, animal studies showed that a single intravenous injection of functionalized nanoparticles significantly reduced macrophage population in tumors within 2 days, and the repeated injections of nanoparticle could help keep the population of the macrophages at a lower level even for 9 days after the first injection[133].

Due to the widely observed serious side effects and badpatient compliance of traditional chemotherapeutic drugs, bioactive macromolecules (such as peptides and gene)such as gene and presenta promising direction in future[134-136]. Yu et al. designed and characterized pH-responsive polymeric micelles that were mannosylated using "click" chemistry to achieve CD206 (mannose receptor)-targeted delivery siRNA to TAMs. Results showed that the mannosylated nanoparticles improved the delivery of siRNA into primary macrophages by 4-fold highercompared with the delivery of a non-targeted carrier. Further, after $24 \mathrm{~h}$ treatment with the mannose-targeted siRNA carriers, $87 \pm$ $10 \%$ knockdowns of a model gene was observed in primary macrophages, a typical cell difficult to transfect, which suggested this polymeric micelles could be used as a promising gene vector targeting TAMs[100].Cieslewicz et al.designed a novel peptide, called M2pep, which could strongly bind to and 
be internalized into M2-likemacrophages responsible for tumor growth and metastasiswhile minimal interaction withM1-like macrophage responsible for anti-tumor property. They used M2pep to carry a pro-apoptotic peptide to TAMs and demonstrated that selective reduction of M2-like TAMs resulted in improved survival in tumor-bearing mice[90].

\subsubsection{Macrophage membrane-camouflaged nanomedicines for cancer treatment}

Recently, bio-mimetic strategies,that nanoparticles are engineered to mimic the cellular functions,are attractingclose attentions for drug delivery application.The innate tumor homing capacity of macrophagescan be employed as a 'Trojan horse' tocamouflage the nanoparticles containing anticancer agents and thenspecifically deliver loaded agents to the tumor[137-140].Cao et al. used macrophage membrane to decorate liposomes to improve tumor-metastasistargeting capability (though $\alpha 4$ integrin-VCAM-1 interactions between macrophages and metastatic cancer cells) and suppress lung metastasis of breast cancer(Fig. 6). Macrophage membranes werefirst isolated from murine monocyte/macrophage cell line RAW 264.7 cells with high expression of $\alpha 4$, and then coated the emtansine liposome with the isolated macrophage membrane to generatea macrophagemembrane-coated emtansine liposome. The results showed that this macrophage membrane decoration increased cellular uptake of the emtansine liposome by metastatic 4T1 breast cancer cells and had significant inhibitory effects on cell viability. In vivo, the macrophage membrane-coated liposome targeted metastatic cells and then produced anobvious inhibitory effect on lung metastasis of breast cancer[89].

Xuan et al. used macrophage cell membrane (MPCM) to decorate gold nanoshells(AuNS) that can serve as a new generation of photothermal conversionagents for in vivo photothermal cancer therapy. Theresulting MPCM-coated AuNSs exhibited good colloidal stability and kept theoriginal near-infrared adsorption of AuNS. Because AuNS carried highdensitycoverage of MPCM, the totally functional portions of macrophage cellsmembrane were grafted onto the surface of AuNS. This surface 
functionalizationprovided active targeting ability by recognizing tumor endothelium and thusimproved tumoraccumulation in comparison to the red blood cell membranecoatingapproach. These biomimetic nanoparticles significantly enhancedin vivoblood circulation and local accumulation at the tumor after beingsystematically administered. Upon laser irradiation, local heat generated by the MPCMcoatedAuNS achieves high efficiency to suppress tumor growth and selectively ablate cancerous cells within the illuminated zone[141].

Those strategies all employed physical interactions between isolated macrophage membrane fragments and inner nanostructured core, the stability issue in circulation will post a big challenge, as complex components in blood may competitively replace the coated macrophage membrane and bind to the surface of inner core, thus leading to unexpected shed off of macrophage membrane and ensuing offtarget accumulation. Hence, how to obtain stable macrophage membrane-derived coating will be a highly concerned point. Our lab exploited click reaction on the basis of bioorthogonal chemistry to get a very stable conjugation bond between macrophage and nanoparticles. For instance, $\mathrm{Xu}$ et al. previouslyfed the RAW 264.7 with azido sugar to let cells express azides on the surface;meanwhile succinimidyl ester DIBO alkyne was coupled to amine-terminated PAMAM dendrimer G4.0 to make clickable dendrimers, and then hybridized macrophage with PAMAM dendrimer was formed via copper-free click reaction. Efficient and selective cell surface modification by dendrimers was confirmed by confocal microscopy. Viability and motility of RAW hybrids remain the same properties as untreated RAW cells according to a series of bioassay. Therefore, this concept shows the feasibility of applying bioorthogonal chemistry to create cell membrane-nanoparticle hybrids and could provide new approach for the nanoparticle surface engineering via cell membrane[142].

In addition to recent advances on TAMs-targeted nanomedicines, novel immunotherapy-based TAMs depletion has also been widely investigated and some of them already entered clinic, which could 
provide us with some powerful support and reference for the design of TAMs-targeted nanomedicines[119, 125, 126, 143].

\subsection{Dysfunctional macrophages in atherosclerosis}

\subsubsection{Involvement of macrophages in the development of atherosclerosis}

During the development of atherosclerosis, macrophages have multiple functions in all phases of atherosclerosis, from development of the fatty streak to ultimate plaque rupture[144, 145].Both the leakiness of endothelial cell junctions in areas of low shear stressand some injury of endothelial cell junction in areas of high shear stress permit excessive blood-derived low-density lipoprotein (LDL) to enter the intima, where itisconverted to oxidized LDL (oxLDL). oxLDL initiates inflammation and upregulates of adhesion molecules, such as P-selectin, intercellular adhesion molecule 1 (ICAM1) and vascular cell adhesion molecule 1 (VCAM1), to recruit leukocytes, like monocytes. Recruited monocytes will adherent to various leukocyte adhesion molecules on the activated endothelial layer, andmigrate into the tunica intima, innermost layer of the arterial wall. Once arrive the arterial intima, monocytes acquire stimulus from oxLDL, undergo a series of morphological changesand ultimately transforminto macrophage. macrophages inside the intima overexpress scavenger receptors (such as the SRA and CD36) and internalize excessive oxLDL though those receptors in a uncontrolled fashion, thus leading to formation of foam cell and ensuing necrosis lipid core, whichconstitute the early atherosclerotic lesionand further propagate the inflammatory cascade(Fig. 7)[146]. Moreover, many evidences based on animal studies have strongly demonstrated that macrophage depletion is highly resistance to development of atherosclerosis. Hence macrophages already becameapromising target for new interventions against atherosclerosis[19, 147, 148].

\subsubsection{Dysfunctional macrophages as a therapeutic target for atherosclerosis treatment}


Based on the vital roles of macrophage during progression of atherosclerosis, there are following aspects that could be considered as potential therapeutictargets to modulate functions of macrophage[18, 149-152], thus preventing development of atherosclerosis: 1) inhibiting leukocyte adhesion[104, 153]; 2) inhibition of LDL oxidation to retard the macrophage activation, for instance, angiotensin-converting enzyme(ACE) inhibitors are reported to increase the resistance of circulatingLDL to oxidation and reduce the development ofatherosclerosis in Apoe $^{-/-}$mice independently out of their bloodpressurelowering effects[154, 155]; 3) suppression of macrophagescavenger receptor activity could potentially reduce theuptake of oxLDL and thus reduce the foam cell formation[105, 156] and 4) regulation of cholesterol homeostasis in macrophage, for example, reduction of cholesterol ester accumulationand increment of cholesterol ester effluxin macrophage within plaques[157, 158].

Many reports proved thatmodulating the polarity of macrophages (M1/M2-like macrophages) toward a less inflammatory directionmay be a potential strategy to preventplaque destabilization and rupture[106, 147, 159, 160].Nakashiro et al. prepared biodegradable poly(lactic-co-glycolic-acid) nanoparticles (NPs) containing pioglitazone(clinically approved potent agonist of peroxisome proliferator-activatedreceptor- $\gamma$ toaffect macrophage polarity), and found that intravenous administration ofNPs incorporated with fluoresceinisothiocyanate wasalmost accumulatedin circulating monocytes and aortic macrophages proved by flow cytometry, which suggested the macrophage-targeting property. Additionally weeklyintravenous administration of pioglitazone-NPs (7 mg/kg per week) for 4 weeks significantly decreased buried fibrous caps, a surrogatemarker of plaque rupture, in the brachiocephalic arteries of Apoe $^{-/}$atherosclerotic mice mainly though suppressing the recruitment of inflammatory monocyte and activating the production of anti-inflammatory M2 macrophage within plaques[104].

In order to suppress the uptake of oxLDL by macrophage and further inhibit formation of foam cell, Dr. Moghe' laboratory designed a library of sugar-based amphiphilic core-shell layered 
nanoparticles (AM NPs), and demonstrated those AM NPs had high binding to scavenger receptor A (SR-A) and CD36 on macrophage and down-regulation of both scavenger receptors, thus preventing oxidized lipid uptake in macrophages and switching them to an atheroprotectivephenotype (Fig. 8). When intravenously administered to a mouse model of cardiovascular disease, these AM NPs showed a pronounced increase in lesion association compared with the control nanoparticles, causing a significant reduction in neointimal hyperplasia, lipid burden, cholesterol clefts, and overall plaque occlusion. Thus, synthetic macromolecules configured as NPs are not only effectively mobilized to lipid-rich lesions but can also be deployed to counteract atheroinflammatory vascular diseases, highlighting the promise of nanomedicines for hyperlipidemia and metabolic syndromes[105].Zhang et al. used 1-(palmitoyl)-2-(5keto-6-octene-dioyl) phosphatidylcholine as a CD36-targeted ligand to improve the macrophage targeting property and antiatherogenic bioactivities of epigallocatechin-3-gallate (EGCG) containing nanoparticle, and the results showed CD36-targeted nanoparticle delivered more EGCG to macrophage cytosol and decrease cholesterol accumulation and inflammatory responses in macrophages, which may in turn prevent atherosclerosis formation and development[161]. To more effectively treat atherosclerosis, the combinations of some therapeutic targets had been attempted as better options to havesynergistic action, such as combination of reducing lipid accumulation and minimizing inflammation. Dr. Moghe' laboratory incorporated the antioxidanta-tocopherol into thecore based on sugar-derived amphiphilic polymers that suppress activity of scavenger receptor for internalizing oxLDL. These composite nanoparticles inhibited keyfeatures of atherosclerosis (modified lipid uptake and the formation of foam cells), while minimizing inflammation in the most advanced ex vivo models available today[162].

Theunderlyingessenceofatherosclerosischaracterizedbythedepositionofcholesterylester(CE)richm acrophagefoamcellsinthearterywall.Althoughsignificantadvanceshavebeenmadetoreducecirculatingchole 
sterollevels,eitherbyinhibitingdenovosynthesis(bystatins)orreducingcholesterolabsorption(byEzetimibe), notherapyiscurrentlyavailabletoefficiently

enhancetheremovalofCEfromexistingatheroscleroticplaquestofacilitateplaqueregression[163,

164].Therefore,theburdenofexistingplaquesinthearteriesandassociatedpathologicalconsequencesstillrema inaftertheseconventionalinterventions, and CE abundant in macrophage within plaques will be a novel target against atherosclerosis.Since only unesterifiedor free cholesterol (FC) can be effluxed from the cells to extracellular cholesterol acceptors, hydrolysis of CEis the obligatory first step in CE mobilization from macrophages. This reaction, catalyzed by neutralcholesteryl ester hydrolase (CEH), is increasingly being recognized as the rate-limiting step in FC efflux, which regulates the process of reverse cholesterol transport and ultimate elimination of cholesterol fromthe body[157]. Hence, our labdeveloped mannose-functionalized dendrimer nanoparticles (DNP) for the specific delivery of LXR ligand (TO901317)[165], which could increase the CEH expression, to plaque associated macrophage in order to enhance the removal of cholesteryl esters (CE) from existing atherosclerotic plaques and facilitate plaque regression. Results showed mannose functionalized DNP could specifically deliver to macrophages and increased CEH expression in vitro as well as in vivo, thus reducing the progression of atherosclerosis.

\subsubsection{HDL as a drug carrier to target dysfunctional macrophage inatherosclerosis}

Additionally, various physiological functions of HDL, such as RCT, anti-oxidation and antiinflammation etc., have always been utilized as cardiovascular drugs carrier to exert synergistic action against atherosclerosis.In addition, natural macrophage-targeted property of high-density lipoprotein (HDL) via scavenge receptor was widely utilized in treatment of atherosclerosis[166-169]. Tang et al. demonstratedthat inhibiting macrophage proliferation or selective depletion of macrophages reduce plaque inflammation and producelong-term therapeutic benefits.He proved that statin-loaded HDL 
nanoparticles(S-HDL)accumulated four-fold higher S-HDL in aortic arch from atherosclerotic Apoe $\mathrm{e}^{-/}$ mice compared to healthy mice and reduced macrophage accumulation in aortic roots by $45 \%$, thus effectively attenuating inflammation in atherosclerosis. She et al. developed a cyclic peptide, LyP-1 (CGNKRTRGC), which specifically targets atherosclerotic plaques,penetrates into plaque interior, and accumulates in plaque macrophages.The results showed that systemic treatment with LyP-1triggered apoptosis of plaque macrophages, reduced plaque inadvanced hypoxic plaques using Apoe $^{-/}$mice atherosclerosis models, and did not increasethe necrotic core of plaques or lead to detectableside effects.With those evidences, peptide LyP-1 could be served as a targeted ligand for the development of newnanomedicines targeting macrophage within atherosclerotic plaques[106].

Duivenvoorden et al. developed reconstituted HDL (rHDL) nanoparticles that delivered statins to atherosclerotic plaques. rHDL labelled with Cy5.5 (lipid monolayer) and DiR (hydrophobic core) was intravenously injected into apoE ${ }^{-/-}$mice. NIRF shows that Cy5.5 and DiR preferentially accumulate in the areas rich in atherosclerotic lesions. Finally 3-month low-dose statin-rHDL treatment inhibited plaque inflammation progression, while one-week high-dose regimen markedly decreases inflammation in advanced atherosclerotic plaques in an $\operatorname{apoE}^{-/-}$mouse model [154]. Zhang et al. constructed recombinant HDL loaded with cardiovascular drug tanshinone IIA (TA) and demonstrated that rHDL containing TA could strongly accumulated in atherosclerotic plaques and had much potent efficacy against advancement of atherosclerosis compared with other conventional nanoparticle-based formulations[170]. However, HDL' nascent receptor SR-B1 is overexpressed not only in the atherosclerotic lesion's macrophage but also in the hepatic hepatocytes, inevitably resulting in the uptake of rHDL by liver [167]. Hence in order to decrease the unintended drug encapsulated in rHDL uptake by liver and actively increase the drug accumulation in atherosclerotic lesions, Liu et al decorated rHDL with macrophage-targeted moiety hyaluronic acid (HA) to decrease the non-targeted uptake by liver and 
deliver a large amount of drug into atherosclerotic lesions so as to efficiently suppress the advancement of atherosclerosis (Fig. 9). Compared with rHDL without HA, HA decoration endowed rHDL with better atherosclerotic plaques targeting property and lower liver accumulation, proved by results from $e x$ vivo imaging and tissue distribution. Furthermore, atheroprotective efficacy in model animal showed that HA-modified rHDL (HA-rHDL) containing Lovastatin (LT) had the best potent efficacy than other LT preparations, which was further demonstrated by the fewest atherosclerotic lesions sizes, the most minimum mean intima-media thickness, the lowest macrophage infiltration and expression of matrix metalloproteinase-9, respectively. Above results demonstrated that the newly designed HA-rHDL could decrease the non-targeted uptake by liver and actively deliver a large amount of drug into atherosclerotic lesions so as to efficiently suppress the advancement of atherosclerosis[171].

\subsubsection{Dysfunctional macrophage as a target for imaging of atherosclerosis}

Atherosclerotic plaques that develop within the arterial wall are hardly observed by conventional angiography and thus it provides few information regarding underlying processes that may lead to plaque rupture. Efficiently plaque-targeted imaging of atherosclerosis is crucial to reveal underlying disease timely. Hence macrophage-targeted strategy was also successfully applied into the imaging of atherosclerosis[146, 172, 173]. Tarin et al. prepared a targeted probe based on gold-coated iron oxide nanoparticles modified with an anti-CD163 antibody, which highly bound to membrane receptor CD163 over-expressed by macrophage at inflammatory sites such as atherosclerosis.The specificity of the targeted probe was validated in vitro by incubation of the probe with $\mathrm{CD} 163(+)$ or $(-)$ macrophages. Subsequently, the targeted probe was injected to 16 weeks old ApoE-deficient atherosclerotic mice and the abdominal aorta was imaged bymagnetic resonance imaging(MRI). The accumulation of probe in the site of plaques increased over time and the signal intensity decreased significantly 48 hours after the injection. It was also reported that CD44 was present in rupture-prone macrophage-rich regions of 
human atherosclerotic plaques at a level over 10 times higher than that in healthy vascular tissues[174]. El-Dakdouki et al. prepared magnetic glyconanoparticles with hyaluronan immobilized on the surface, which could selectively bind CD44. In $\mathrm{T}^{+}$weighted MRI, significant contrast changes in aorta walls were observed only with a very low dose of the magnetic nanoparticles, allowing the effective detection

of atherosclerotic plaques[175]. As a ligand for SR-A overexpressed by activated macrophages within atherosclerotic plaques, dextran sulfate (DS) was employed by You et al. to coat superparamagnetic iron oxide nanoparticles (DS-SPIONs) to prepareMRI contrast agent of atherosclerosis[176]. Similar macrophage-targeted strategies for imaging of atherosclerosis were also reported based onHDL[169, 177, 178], CD36[161, 179, 180] and CD44[171, 175]as macrophage targeted moieties.

\subsection{Dysfunctional macrophages in rheumatoid arthritis (RA)}

RA, as an autoimmune disease with unknown initiator, is highly characterized by chronic systemic inflammation that predominantly affects articular tissue. It is wellacknowledgedthat macrophage could act as amplifiers of local and systemicinflammation, with a direct contribution to matrix degradation[11, 12].At a systemic level, monocytes are first attracted to the RA joint, where they differentiate into macrophages and become activated. Active macrophage then secrete TNF- $\alpha$ and IL1,which induce synovial fibroblasts to express cytokines (such as IL-6 and IL-8), growth factors (such as granulocyte-macrophage colony-stimulating factor) and matrix metalloproteinases (MMPs) that contribute to cartilage and bone destruction. TNF- $\alpha$ also increases the expression of adhesion molecules on endothelial cells, which could recruit more monocytes to the joint andenhances macrophage activation and differentiation(Fig. 10)[181, 182]. The augment of subliming macrophages in the synovium is a prominent feature of inflammatory lesions and an early symbol of active rheumatic disease. The degree of synovial macrophage infiltration positively correlates with the degree of joint erosion, and depletion of these macrophages from inflamed tissue could produce a profound therapeutic 
benefit[183-185]. Hence, the central role of activated macrophages in inflammation and bone homeostasis as well as modulating the cytokine environment in systemic arthritis make themsuitable for a strong target in the treatment of RA[14]. Currently the antimacrophage therapycounteracting activation of macrophagemainly focuses on: 1) down-regulate the production of pro-inflammatory cytokines produced by active macrophage; 2) eliminatedysfunctional macrophage physically from theinflammatory foci or systemic loci and 3) upregulate the anti-inflammatory cytokines.

The inflamed regions of RA display excessively infiltrated pro-inflammatory cytokines includingtumor necrosis factor- $\alpha$, IL-1, IL-6 and IL-8that proactively contribute to hyperplasia of synovial membrane, bone erosion, and cartilage destructions in joints. Hence suppression of those proinflammatory cytokines produced by active macrophagein synovial tissues has becoming a novel therapeutic target in RA therapy[186-188].For instance Notch1, a signaling receptor, plays important roles in the regulation of inflammatory responses in many diseases like rheumatoid arthritis. Suppression of Notch signaling with $\gamma$-secretase inhibitor has shown to reduce the severity of inflammatory arthritis[189, 190]. Kim et al. fabricated Notch1 targeting siRNA delivery nanoparticles (siRNA-NPs) via self-assembled poly-siRNA and thiolated-glycol chitosan nanoparticles (Fig 11)[191]. The results showed that siRNA-NPs enhanced target ability ofactive macrophage in synovial jointsvia the enhanced permeation and retention (EPR) effectandthus prevented the undesired therapeutic outcome induced by non-specific inhibition of Notch1 pathway in normal tissues. In vivo studies demonstrated that siRNANPs significantly inhibited Notch1 pathway, thus retarding progression of inflammation, bone erosion, and cartilage damage in CIA mice without undesirable severe toxicity.In order to quench the inflammation produced by active macrophage in RA sites, Hayder et al. demonstrated intravenous injection of azabisphosphonate (ABP)-capped dendrimer targeted inflammatory macrophage within RA, 
directed them toward anti-inflammatory activation and thus inhibited the development of inflammatory arthritis in two animal models[192].

Severity of rheumatoid arthritis has been directly linked to the number of macrophages present in the arthritic synovium. Such pro-inflammatory macrophage activation in the diseased state has been termed as M1-macrophage phenotype. Alternatively, macrophages involved with anti-inflammatory processes are considered to be M2-likephenotype. Therefore, strategies that can effectively switch macrophage from predominant M1 in the synovium to M2 state may be potential to the treatment of rheumatoid arthritis.Depletion of systemic and joint macrophages with clodronate loaded liposomes is not a viable strategy given the key role of macrophage in immuno-surveillance[183]. Jain et al. selectively modified the macrophage phenotype by delivering an anti-inflammatory cytokine (Interleukin 10) encoding plasmid DNA encapsulated into a nanoparticle system modified with tuftsin peptide to achieve active macrophage targeting. Enhanced localization of tuftsin-modified alginate nanoparticles was observed in the inflamed paws of arthritic rats upon intraperitoneal administration. Importantly, targeted nanoparticle treatment was successful in reprogramming macrophage phenotype balance as $\sim 66 \%$ of total synovial macrophages from arthritic rats treated with the IL-10 plasmid DNA loaded tuftsin-alginate nanoparticles were in the M2 state compared to 9\% of macrophages in the M2 state from untreated arthritic rats. Treatment significantly reduced systemic and joint tissue proinflammatory cytokines (TNF- $\alpha$, IL-1b, and IL-6) expression and prevented the progression of inflammation and joint damage as revealed by magnetic resonance imaging and histology[96].

Among the key molecules involved in inflammation and the family of phospholipase A2 (PLA2) enzymes, cPLA2 $\alpha$ is one of the most expressed one in active monocytes/macrophages and regulates normal and pathologic processes through arachidonic acid release from phospholipid membranes, used as substrates for the synthesis of lipid mediators, including prostaglandins and leukotrienes, that play 
critical roles in the development and maintenance of inflammation[13]. Courties et al. applied siRNA technology combined with use of cationic liposome that was able to efficiently transfect monocytic cells in vivo, thusspecifically silencing the expression of cPLA2 $\alpha$ in functionally relevant cell types in an experimental model of RA. Results indicated that systemic siRNA-mediated cPLA2 $\alpha$ gene silencing was effective for the treatment of collagen-induced arthritis[94].

\subsection{Dysfunctional macrophages in inflammatory bowel disease (IBD)}

Macrophages are an integral part of the normal intestinal tissues and well located in lamina propria and Peyer's patch, where they play as an immune effector cells against any pathogenic attack. In the healthy intestine, macrophages in laminado not induce strong pro-inflammatory responsesagainst either microbial ligands or host cytokines/chemokines. While under stimulation from an inflammatory signal, inflammatory monocytes are recruited from blood and then transformed into inflammatorymacrophages in the lamina propria, and unlike resident macrophagesinflammatorymacrophages would greatly produce severe intestinal inflammatory reactionand tissue damage byover-expressingtriggering receptor expressed on the surface of myeloid cells, nod-like receptors (NLRs), toll-like receptors (TLRs) and TNF- $\alpha[15,16,193,194]$.Recent studies

have also demonstrated that depletion of macrophages in the IL10 ${ }^{-/-}$mouse prevents development of colitis[195]. Therefore inflammatorymacrophages within intestine present as attractive targeting strategy for treating inflammatory bowel disease.

Accumulating evidences have shown that macrophage contribute to IBD progression by producing pro-inflammatory cytokines such as TNF- $\alpha$. Therapeutic strategies against TNF- $\alpha$ have been shown to effectively treat IBD in multiple clinical trials using the monoclonal antibody infliximab[195197].However, serious infections and side effects have been associated, including immunodeficiencyrelated infections and formation of antibody against TNF- $\alpha$.Therefore anti-TNF- $\alpha$ therapeutic agents 
need to be targeted delivery toinflammatory sites. With the advance of nanotechnology and gene therapy, gene silencing via siRNA represents a promising treatment strategy for intestinal inflammation[99, 198].Zhang et al. developed galactosylated trimethyl chitosan-cysteine (GTC) nanoparticles (NPs) to orally deliver a mitogen-activated protein kinase-kinase-kinase-kinase 4 (Map4k4) siRNA (siMap4k4), a key upstream mediator of TNF- $\alpha$ action, to the activated macrophages for treatment of dextran sulfate sodium (DSS)-induced ulcerative colitis (UC). The in vitro and in vivo gene knockdown tests showed that siMap4k4 loaded NPs effectively inhibited TNF- $\alpha$ production accompanied with significant histological improvements from H\&E-stained colonic sections[101]. Laroui et al.also proved that biodegradable, non-cytotoxic polylactide nanoparticles (NPs) containing TNF $\alpha$ siRNA/polyethyleneimine (PEI) complexwere efficiently taken up by inflamed macrophages and thus significantlyinhibit TNF- $\alpha$ secretion by the macrophages.In vivo studies showed that TNF $\alpha$ siRNA/PEIloaded NPs were efficiently delivered to the colonic tissue and that TNF- $\alpha$ siRNA released from NPs efficiently inhibited LPS-induced synthesis/secretion of colonic TNF- $\alpha$ [99]. In order to improve the macrophage targeting properties,Xiao et al. synthesizeda macrophage-targeted bioreducible cationic polymer conjugate with sodium triphosphate (TPP) as gene delivery for TNF- $\alpha$ siRNA (Fig. 12). These NPs were efficiently taken up by macrophages and conferred high-level RNAi, which remarkablydecreased TNF- $\alpha$ expression and had potent anti-inflammatory effects both in vitro and ex vivo[100].

In order to obtain the criterion of both colonic sustained release of TNF- $\alpha$ siRNA and macrophages targeting delivery at the same time, Huang et al. developed an orallyadministrated nanoparticle that could actively target the colonic macrophages and suppressed the localexpression of TNF-a for IBD. This vehicle was constructed by cationic konjac glucomannancomposed of mannoseand b-glucan (cKGM),phytagel and an antisense oligonucleotide (ASO) against TNF- $\alpha$. It was given to 
dextran sodium sulfate (DSS)colitic mice via gastric perfusion. The distinctive swelling properties of cKGM allowed for the spontaneousrelease of cKGM\&/ASO nanocomplex from the phytagel matrix into the colonlumen, where the ASO was efficiently internalized into colonic macrophages via mannose receptor-mediated endocytosis.The administration of this nanoformulation significantly decreased the expression level of TNF-aand alleviated the symptoms of colitis inthe dextran sodium sulfate-induced colitic mice. [98].

\subsection{Dysfunctional macrophages in obesity and ensuing insulin resistance for type 2 diabetes}

Macrophages only constitute $10-15 \%$ of the cell population in the lean adipose tissue, where they predominantly exhibit an anti-inflammatory phenotype, classically termed as M2-like state. However, in obese humans and rodents, macrophages make up 40-50 \% of the interstitial cell population in the adipose tissue, dubbed as adipose tissue macrophages (ATMs), and switch phenotype to a more pro-inflammatory M1-like state, which are a major source of pro-inflammatory cytokinessuch as tumor necrosis factor $\alpha(\mathrm{TNF} \alpha)$ that can function in a paracrineand potentially an endocrine fashion to causeinsulin resistance. The causal relationship between obesity and type 2 diabetes has recently been generally identified as chronic low-grade systemic inflammation induced by pro-inflammatory M1-like macrophages in those obese adipose tissues.Pharmacological or genetic inhibition of pathways had proved that attenuating inflammatory responses could protect experimental animals and human subjects from obesity-induced insulin resistance[21, 23, 199].

Most clinical therapiestoinflammation involved in obesity-relatedcomplications focus on antiinflammatory drugs such as nonsteroidal anti-inflammatory drugs (NSAIDs), aspirin and glucocorticoids (like dexamethasone), which have been widely used in the clinic by obese and/or diabetic patients for few decades[200-202]. However, high doses and long term administration are always accompanied with serious adverse effects, including bleeding, gastrointestinal irritation and Cushing-like syndrome etc. 
More clinical evidences suggest that those side effects result from the drugs'off-target effect, particularly liver hepatocytes, muscle cells and enterocytes.Hence specifically targeting ATMsvia nanomedicinescould substantially resolve those limitations and improve the therapeutic outcomes[21, 179].

Ma et al reported that nanoscale polysaccharides based on biocompatible glucose polymers can efficiently target adipose macrophages in obese mice (Fig. 13). The results suggested that nanocarriers with size in 70-500 nm efficiently distributed to visceral adipose tissue and selectively bond with macrophages after regional peritoneal administration. Up to $63 \%$ of the injected dose remained in visceral adipose tissue $24 \mathrm{~h}$ after administration, leading tomore than 2-fold higher local accumulationin comparison to liver, which is the dominant site of uptake for most nanomedicines. Furthermore, a single-dose administration significantly reduced pro-inflammatory markers in adipose tissue of obese mice[111].

$\operatorname{PPAR} \gamma$ nuclear receptor agonists have been shown to attenuate macrophage inflammatory responses implicated in the obesity[203, 204].However, current PPAR $\gamma$ agonists in clinic, such as rosiglitazone (RSG), are often associated with severe adverse effects that greatly limit their therapeutic effect. Mascolo et al. synthesized polymeric NPs with a diameter of around $200 \mathrm{~nm}$ as RSG delivery vehicle (RSG-NPs), which could be preferentially taken up by circulating monocytes, residing in the liver (kupffer cells) and in the white adipose tissue (WAT).In $\mathrm{ldlr}^{-/-}$mice fed high fat diet, treatment with RSG-NPs alleviated inflammatory reaction in white adipose tissue and liver.In addition unlike treatment with free RSG,RSG-NPs did not alter genes related to normal lipid metabolism or cardiac function, suggesting anobvious reduction offree RSG-related side effects[110].

Obesity and its related metabolic syndromes like diabetesarealso closely related with the microenvironment within adipose tissue[205, 206]. A major reason of obesity is that the over-eating of 
energy-rich food accumulates in the parenchymal adipocytes of adipose tissue, particularly in liver and muscles. This process is termed as adipogenesis thathighly needs the simultaneous development of angiogenesis[207]. Therefore, it would be anticipated that efficiently suppressing angiogenesis could inhibit adipocyte hyperplasia and thus palliate insulin resistance by reducing the infiltration of inflammatory macrophages into adipose tissue. To target angiogenic vessels in obese fat tissues, Hossen et al. designed prohibitin (an adipose vascular marker)-targeted nanoparticle (PTNP) encapsulatingcell death-inducingpeptide [D(KLAKLAK)2] via modification by a linear peptide containing a white fat vessels targeting motif (KGGRAKD). Treatment with PTNP caused a potential antiobesity effect on dysfunctional adipose cells, including adipocytes and macrophages, suggesting that vascular-targeted nanomedicine may be effective for the control of the adipose function and peripheral fat deposition in the body. In addition, drug delivery via the PTNP system, that was actively accumulated in obese fat mediated by its multivalent active targeting, resulted in a subsequent enhancement in drug delivery to adipose endothelial cells[112].

Some innovative anti-obesity therapies also realize with the extension of understanding for progression ofobesity[208]. Recent evidences showed obesity is highly related to an expansion and proliferation of white adipose tissue (WAT) in the body. The primary function of WAT is to store energy, whereas brown adipose tissue (BAT) generates heat through energy expenditure. TransformingWAT into BAT is of great interest for obesity treatment. Xue et al. engineered a targeted nanoparticle through self-assembly of a biodegradable triblock polymer PLGA-b-PEG and an endothelial-targeted iRGD peptide, which can actively bind to angiogenic vessels through integrinavb3/b5 receptors and WAT vasculature through the membrane protein prohibitin. Here they used this functionalized nanoparticle to deliver either Peroxisome Proliferator-Activated Receptor gamma activator rosiglitazone or prostaglandin E2 analog toadipose tissue vasculature,each of which 
could induce adipose tissue transformation and angiogenesis, thus facilitating the transformation of WAT into BAT. The in vivo results showed that i.v. administration of these NPs actively targeted WAT vasculature stimulated the angiogenesis that is required for the transformation of adipose tissue, and transformed WAT into BAT, by the up-regulation of angiogenesis and brown adipose tissue markers. In a diet-induced obese mouse model, these angiogenesis-targeted NPs inhibited body weight gain and modulated several serological markers including cholesterol, triglyceride, and insulin, compared with the control group. These findings suggest that angiogenesis-targeting moieties-modified NPs containing angiogenic stimulator could be an effective therapeutic regimens for clinical treatment of obesity and other metabolic diseases[113].

Type2-diabetes is alsocharacterized by microvascular changes and monocyte recruitment and macrophage activation. A major limitation to better understanding, preventing, and curing diabetes has been the inability to "monitor" the disease initiation, progression, or regression, especially during the latent phase. Hence early diagnosis and monitoring of disease progression for patients with diabetes could benefit a lot to both patients and caregivers[209-211]. In apilot clinical study, non-diabetic healthy volunteers andpatients with onset diabetes were administrated with aclinically approved MRI contrastimagingagent, based on the dextran-coated iron oxidenanoparticle thatis readily taken up by macrophagesowing to its size and surface properties, allows for the effective visualization of the pancreas and distinction of onset diabetes patients from nondiabetic controls[20].

\subsection{Dysfunctional macrophages in human immunodeficiency virus type I (HIV-1)}

HIV infection is still a severe global life-threatening concern accounting for more than 25 million deaths in last three decades. More than 34 million people are living with HIV infection. As one of cell types easily infected by HIV-1, macrophage, that has to be mentioned, plays a crucial role in the different phases of HIV-1 infection, including HIV-1 transmission through the whole body, the acute 
and chronic phases of HIV-1 infection, the development of acquired immunodeficiency syndrome (AIDS) and HIV-associated diseases, including neurocognitive disorders[25].Macrophage, similar to $\mathrm{CD}^{+} \mathrm{T}$ helper cells, also expresses high levels of the HIV-1 receptor CD4 on their surface and is highly permissive for HIV-1 infection. First step of HIV-1 infects host cells via virus ligand (surface glycoprotein gp120), which interacts with HIV-1 receptor CD4 receptor present in both T cells and macrophages. Second step involves the fusion of viral envelope with host cell membrane mediated by the engagement of the co-receptors (CCR5). At the first phage, macrophages are critically involved in the initiation and the orchestration of the adaptive cellular and humoral immune response that helps to diminish viral infection;while with the advancement of HIV-1 infection, highly migratory infectedperivascular macrophages will be served as a reservoir to hijack and disseminate the virus throughout the body. [6, 212-214].Besides, HIV-infected macrophages in lymph nodes express the viral protein Nef, which will be shuttled to B cells. After reaching B lymphocytes, Nef affects cellular functions and interruptthe B cell function(Fig.14).In addition,Nef-activated and HIV-1 infected macrophages might also be critically related to the apoptosis of $\mathrm{CD} 4^{+}$and $\mathrm{CD} 8^{+} \mathrm{T}$ cells[215].

The current foundation of HIV-1 therapy is still based on antiretroviral therapy (ART).However, long term treatment of ART cannot eliminate all infected cells from the patients, and virus levels rapidly rebound once ART treatment is stopped. The main reasons for recurrenceare due to 1) the plenty persistencelong-lived HIV-1reservoirs like macrophage; 2)eradication of HIV-1 from those reservoirs is difficultly feasible, because HIV-1 produced by tissue-associated macrophages might be targeted insufficiently by antiviral drugs due to the low bioavailability of the drugs in certain tissues; 3) multidrug pumps on macrophage render HIV-1 resistant toward HIV-1 protease inhibitorsthoughreduction of the concentration of inhibitors within the macrophage, thus decreasing concentrations of the anti-HIV drugs and possibly promoting the emergence of escape mutants[25, 26, 
117, 216].Therefore, it is crucial to develop novel therapeutic options to target HIV-1 reservoirs to potentially reduce the required drug dosage, shorten the duration of treatment, mitigate dose-dependent toxicity, and reduce the emergence of drug resistance. Macrophages,one of the most important HIV-1 reservoirs, are responsible for transmitting HIV-1. Failure to eliminate HIV-1 reservoir underpins the limitations of current ARV therapies. Thus eradicating HIV-1 infected macrophage has emerged as a promising solution for effective anti-HIV-1[217, 218]. In order to targeted delivery of ARV to HIT-1 infected macrophage, Kutscher et al employed 1,3- $\beta$-glucan (GLU) as macrophage-targeting ligand to functionalize chitosan (CS) shell and (PLGA) core nanoparticles loaded with the ARV nevirapine (GLU-CS-PLGA). Specific GLU interaction with recognition receptor dectin-1on the surface of macrophages enhancedthe intracellular ARV delivery.Ex vivo imaging showed that these functionalized nanoparticles actively targeted macrophages in the liver and kidney[117].Ghosh et al. also achieved enhanced macrophage-specific delivery of anti-AIDS drug stavudine and improved in vivobehaviors through optimized PLGA nanoparticles as drug carriers[219].

Based on the advancement of molecular probing, more and more essential elements, such as proteins, enzymes and receptors, intimatelyinvolved in the infection and transmission of HIV-1 have been recognized. Those elements could be served as potential target for discovery of anti-HIV-1 regimen. Galectin-1, an adhesion molecule, is expressed in macrophages and implicated in HIV-1 viral adsorption to the host cell.Reynolds et al. demonstrated thatgalectin-1 siRNA delivered by gold nanorod efficiently inhibitedgalectin-1 gene expression on the macrophage, which could potentially reduce the galectin-1-mediated HIV-1 infection[220].The CCR5 protein belongs to the beta chemokine receptors family of integral membrane proteins and is predominantly expressed on HIV-1 host cells, including T cells, macrophages and dendritic cells etc.CCR5 also plays very essential roles for the entry of HIV-1 to target immunological cells like macrophage and later transmission during the acute infection. HIV-1 
viral entry to host cells is collaborativelyaccomplished by the first binding of viral gp120 to host HIV-1 receptor CD4 and subsequent binding to a cellular co-receptor CCR5. Following co-receptor binding, HIV-1 stably anchors to the host cell membrane, thus leading to viral-cell membrane fusion and insertion of the viral nucleotides into the host cell. Hence, the co-receptor CCR5 could be a possible target for design of viral-infected host cell-targeted anti-retroviral agent delivery system. Bronshtein et al. used cytoplasmic membranes from cells expressing CCR5to decorate liposomes containing toxin EDTA to target the HIV-infected cells(Fig. 15).These results demonstrated the CCR5-expressing cell membrane-derived liposomes specifically targeted towards gp120-expressing HIV model cells, and led to $60 \%$ reduction in the viability of gp120-expressing cells compared to no effect on control cells that do not express gp120, which suggesting the targeted-binding between CCR5 and gp120[221].

Macrophage also serves as targets for AIDS relevant pathogens, e.g. Mycobacterium tuberculosis (TB), thereby fueling the establishment of opportunistic infections associated with the progression of AIDS.It is estimated that one third of HIVinfected individuals are co-infected with TB. In addition, TB infection in HIV-1 positive patients appearsto amplify the HIV-1 production, resulting in increased HIV1 viremia and hastening the progression of HIV-1disease. Furthermore, HIV-1 infection in itself also impairs appropriate immune response to the infection from TB, enhancingthe progression and severity of TB.Therefore, establishing effective regimen for co-infection of HIV-mycobacterium could provide some promising clinical outcomes for late phase HIV patients.

Narayanasamy et al.developeda kind of Gallium (Ga) nanoparticles which could reside inside the macrophages for a longer time.Gais a metal highly similarto iron (Fe) that is crucial to the metabolism and growth of most microbes, including HIV. While unlike $\mathrm{Fe}^{+} 3, \mathrm{Ga}^{+} 3$ cannot be reduced and thus once bound to Fe binding sites in an enzyme, the enzymewill be inactivated. Thus, all Fe-dependent pathways both in bacteria and virus would be potentially blocked by the presence of Ga, leading to growth 
inhibition and ensuing death. Ga is also not susceptible to classical drug efflux pumps and thereforeless vulnerable to generally encountered antibiotic resistance mechanisms. Results clearly showed that the Ga nanoparticle was highly internalized by macrophage and was maintained sustained-release for up to 15 days, and significantly inhibited growth of both HIV and mycobacterium in the macrophagefor up to 15 days following single drug loading[222].

\section{Concluding remarks and future perspectives}

Dysfunctional macrophages play critical rolesin the evolution of various diseases such as cancer, inflammatory and autoimmune disorders. Due to their plasticity, macrophages undergo phenotypical and functional switches with the advancement of many diseases. Identification of distinct diseasespromoting macrophage subsets would lay a solid foundation for development of macrophage-targeting strategies to eliminate or correct those macrophages.Macrophage subtype populationsare not limited topro-inflammatory M1-like macrophages and anti-inflammatory M2-like macrophages. For instance, M2-like macrophage are alsoconsidered tumor-associated macrophages promoting the progression of the tumor tissue and helpingtumor cellsescape from the immune system. Therefore, blockade of dysfunctional macrophage accumulation, restoration of biological function and conversion of macrophage in diseases'focifrom the pathogenicone back to therapeuticone will become important therapeutic strategiesin future.

While much advances have already been made, there is room for improving the efficacy of targeting dysfunctional macrophages in diseases' site. Questions as to how to correctly modulate functions of specific macrophage phenotype to reach therapeutic intervention, how to monitor therapeutic response accurately and timely, and how to avoid the compromisedimmuneprotectivefunctions of macrophage caused by therapeutic intervention, and many others remain yet to be fully addressed. To translate macrophagetargeting nanomedicines from bench to bedside, some 
directions may be taken into account:1) relationships between macrophages and nanoparticlesshall befully elucidated and utilized to better achieve macrophage-specific targeting;2) It is desirable to developtheranostic nanomedicines that incorporate both diagnostic probe (or imaging) and therapeutic agents in a single system, enabling visualizingand monitoringthe progression of diseases timely during treatments; 3) Thorough in vivoinvestigations shall be conducted, such as PK/PD, metabolism and longterm toxicity studies. We are optimistic that nanoparticle-based nanomedicines will help target specific macrophages to better treat dysfunctional macrophages-associated diseases by combining the in-depth understandings of complex relationships between macrophages and diseases’ progression and advances in nanotechnology.Acknowledgements

This work was supported by VCU's CTSA (UL1TR000058 from the National Center for Advancing Translational Sciences) and the CCTR Endowment Fund of Virginia Commonwealth University to HY and SG as well as NSF CAREER award CBET0954957. 


\section{References}

[1] T.A. Wynn, A. Chawla, J.W. Pollard, Macrophage biology in development, homeostasis and disease, Nature, 496 (2013) 445-455.

[2] J. Hettinger, D.M. Richards, J. Hansson, M.M. Barra, A.-C. Joschko, J. Krijgsveld, M. Feuerer, Origin of monocytes and macrophages in a committed progenitor, Nature immunology, 14 (2013) 821-830.

[3] S. Epelman, K.J. Lavine, G.J. Randolph, Origin and functions of tissue macrophages, Immunity, 41 (2014) 2135.

[4] P.J. Murray, T.A. Wynn, Protective and pathogenic functions of macrophage subsets, Nature reviews immunology, 11 (2011) 723-737.

[5] K.M. Lee, C. Yin, C.P. Verschoor, D.M. Bowdish, Macrophage function disorders, eLS, (2001).

[6] P. Bhargava, C.-H. Lee, Role and function of macrophages in the metabolic syndrome, Biochemical Journal, 442 (2012) 253-262.

[7] J.C. McNelis, J.M. Olefsky, Macrophages, immunity, and metabolic disease, Immunity, 41 (2014) 36-48.

[8] M. De Palma, C.E. Lewis, Macrophage regulation of tumor responses to anticancer therapies, Cancer cell, 23 (2013) 277-286.

[9] C.I. Diakos, K.A. Charles, D.C. McMillan, S.J. Clarke, Cancer-related inflammation and treatment effectiveness, The Lancet Oncology, 15 (2014) e493-e503.

[10] G. Germano, R. Frapolli, C. Belgiovine, A. Anselmo, S. Pesce, M. Liguori, E. Erba, S. Uboldi, M. Zucchetti, F. Pasqualini, Role of macrophage targeting in the antitumor activity of trabectedin, Cancer cell, 23 (2013) 249262.

[11] G.S. Firestein, Evolving concepts of rheumatoid arthritis, Nature, 423 (2003) 356-361.

[12] R.W. Kinne, R. Bräuer, B. Stuhlmüller, E. Palombo-Kinne, G.-R. Burmester, Macrophages in rheumatoid arthritis, Arthritis Research \& Therapy, 2 (2000) 1.

[13] I.B. McInnes, G. Schett, Cytokines in the pathogenesis of rheumatoid arthritis, Nature Reviews Immunology, 7 (2007) 429-442.

[14] U. Müller-Ladner, T. Pap, R.E. Gay, M. Neidhart, S. Gay, Mechanisms of disease: the molecular and cellular basis of joint destruction in rheumatoid arthritis, Nature clinical practice Rheumatology, 1 (2005) 102-110.

[15] S.E. Heinsbroek, S. Gordon, The role of macrophages in inflammatory bowel diseases, Expert reviews in molecular medicine, 11 (2009) e14.

[16] R. Xavier, D. Podolsky, Unravelling the pathogenesis of inflammatory bowel disease, Nature, 448 (2007) 427-434.

[17] G.S. Hotamisligil, Inflammation and metabolic disorders, Nature, 444 (2006) 860-867.

[18] A.C. Li, C.K. Glass, The macrophage foam cell as a target for therapeutic intervention, Nature medicine, 8 (2002) 1235-1242.

[19] K.J. Moore, F.J. Sheedy, E.A. Fisher, Macrophages in atherosclerosis: a dynamic balance, Nature Reviews Immunology, 13 (2013) 709-721.

[20] M.J. Kraakman, A.J. Murphy, K. Jandeleit-Dahm, H.L. Kammoun, Macrophage polarization in obesity and type 2 diabetes: weighing down our understanding of macrophage function?, M1/M2 Macrophages: The Arginine Fork in the Road to Health and Disease, (2015) 195.

[21] J.M. Olefsky, C.K. Glass, Macrophages, inflammation, and insulin resistance, Annual review of physiology, 72 (2010) 219-246.

[22] G. Tesch, Role of macrophages in complications of type 2 diabetes, Clinical and Experimental Pharmacology and Physiology, 34 (2007) 1016-1019.

[23] A. Castoldi, C.N. de Souza, N.O.S. Câmara, P.M. Moraes-Vieira, The macrophage switch in obesity development, Frontiers in immunology, 6 (2015).

[24] J.B.C. Carvalheira, Y. Qiu, A. Chawla, Blood spotlight on leukocytes and obesity, Blood, 122 (2013) 32633267.

[25] H. Koppensteiner, R. Brack-Werner, M. Schindler, Macrophages and their relevance in Human Immunodeficiency Virus Type I infection, Retrovirology, 9 (2012) 1. 
[26] A. Kumar, G. Herbein, The macrophage: a therapeutic target in HIV-1 infection, Molecular and cellular therapies, 2 (2014) 1.

[27] J.B. Mitchem, D.J. Brennan, B.L. Knolhoff, B.A. Belt, Y. Zhu, D.E. Sanford, L. Belaygorod, D. Carpenter, L. Collins, D. Piwnica-Worms, Targeting tumor-infiltrating macrophages decreases tumor-initiating cells, relieves immunosuppression, and improves chemotherapeutic responses, Cancer research, 73 (2013) 1128-1141.

[28] F. Chellat, Y. Merhi, A. Moreau, L.H. Yahia, Therapeutic potential of nanoparticulate systems for macrophage targeting, Biomaterials, 26 (2005) 7260-7275.

[29] C. Kelly, C. Jefferies, S.-A. Cryan, Targeted liposomal drug delivery to monocytes and macrophages, Journal of drug delivery, 2011 (2010).

[30] W. Xia, A.R. Hilgenbrink, E.L. Matteson, M.B. Lockwood, J.-X. Cheng, P.S. Low, A functional folate receptor is induced during macrophage activation and can be used to target drugs to activated macrophages, Blood, 113 (2009) 438-446.

[31] S. Svenson, R.K. Prud'homme, Multifunctional nanoparticles for drug delivery applications: imaging, targeting, and delivery, Springer Science \& Business Media, 2012.

[32] B.L. Chung, M.J. Toth, N. Kamaly, Y.J. Sei, J. Becraft, W.J. Mulder, Z.A. Fayad, O.C. Farokhzad, Y. Kim, R. Langer, Nanomedicines for endothelial disorders, Nano today, 10 (2015) 759-776.

[33] T.M. Allen, P.R. Cullis, Drug delivery systems: entering the mainstream, Science, 303 (2004) 1818-1822.

[34] S.M. Moghimi, A.C. Hunter, J.C. Murray, Nanomedicine: current status and future prospects, The FASEB journal, 19 (2005) 311-330.

[35] T. Sun, Y.S. Zhang, B. Pang, D.C. Hyun, M. Yang, Y. Xia, Engineered nanoparticles for drug delivery in cancer therapy, Angewandte Chemie International Edition, 53 (2014) 12320-12364.

[36] V. Wagner, A. Dullaart, A.-K. Bock, A. Zweck, The emerging nanomedicine landscape, Nature biotechnology, 24 (2006) 1211-1217.

[37] D.K. Kim, J. Dobson, Nanomedicine for targeted drug delivery, Journal of Materials Chemistry, 19 (2009) 6294-6307.

[38] P. Couvreur, Nanoparticles in drug delivery: past, present and future, Advanced drug delivery reviews, 65 (2013) 21-23.

[39] R. Gref, A. Domb, P. Quellec, T. Blunk, R. Müller, J. Verbavatz, R. Langer, The controlled intravenous delivery of drugs using PEG-coated sterically stabilized nanospheres, Advanced drug delivery reviews, 64 (2012) 316-326.

[40] T.M. Allen, P.R. Cullis, Liposomal drug delivery systems: from concept to clinical applications, Advanced drug delivery reviews, 65 (2013) 36-48.

[41] B.S. Pattni, V.V. Chupin, V.P. Torchilin, New developments in liposomal drug delivery, Chemical reviews, 115 (2015) 10938-10966.

[42] B. Kneidl, M. Peller, G. Winter, L.H. Lindner, M. Hossann, Thermosensitive liposomal drug delivery systems: state of the art review, International journal of nanomedicine, 9 (2014) 4387.

[43] M. Nirmala, R. Nagarajan, Microemulsions as Potent Drug Delivery Systems, J Nanomed Nanotechnol, 7 (2016) e139.

[44] F. Muzaffar, U. Singh, L. Chauhan, Review on microemulsion as futuristic drug delivery, Int J Pharm Pharm Sci, 5 (2013) 39-53.

[45] L. Xu, Y. Liu, Z. Chen, W. Li, Y. Liu, L. Wang, L. Ma, Y. Shao, Y. Zhao, C. Chen, Morphologically Virus - Like Fullerenol Nanoparticles Act as the Dual - Functional Nanoadjuvant for HIV - 1 Vaccine, Advanced Materials, 25 (2013) 5928-5936.

[46] Y. Miura, T. Takenaka, K. Toh, S. Wu, H. Nishihara, M.R. Kano, Y. Ino, T. Nomoto, Y. Matsumoto, H. Koyama, Cyclic RGD-linked polymeric micelles for targeted delivery of platinum anticancer drugs to glioblastoma through the blood-brain tumor barrier, ACS nano, 7 (2013) 8583-8592.

[47] P. Kesharwani, K. Jain, N.K. Jain, Dendrimer as nanocarrier for drug delivery, Progress in Polymer Science, 39 (2014) 268-307.

[48] S. Svenson, D.A. Tomalia, Dendrimers in biomedical applications-reflections on the field, Advanced drug delivery reviews, 64 (2012) 102-115. 
[49] J. Yang, Q. Zhang, H. Chang, Y. Cheng, Surface-engineered dendrimers in gene delivery, Chemical reviews, 115 (2015) 5274-5300.

[50] A. Baeza, M. Colilla, M. Vallet-Regí, Advances in mesoporous silica nanoparticles for targeted stimuliresponsive drug delivery, Expert opinion on drug delivery, 12 (2015) 319-337.

[51] C. Giménez, C. de la Torre, M.n. Gorbe, E. Aznar, F.l. Sancenón, J.R. Murguía, R. Martínez-Máñez, M.D. Marcos, P. Amorós, Gated mesoporous silica nanoparticles for the controlled delivery of drugs in cancer cells, Langmuir, 31 (2015) 3753-3762.

[52] A.M. Alkilany, L.B. Thompson, S.P. Boulos, P.N. Sisco, C.J. Murphy, Gold nanorods: their potential for photothermal therapeutics and drug delivery, tempered by the complexity of their biological interactions, Advanced drug delivery reviews, 64 (2012) 190-199.

[53] S. Rana, A. Bajaj, R. Mout, V.M. Rotello, Monolayer coated gold nanoparticles for delivery applications, Advanced drug delivery reviews, 64 (2012) 200-216.

[54] L. Vigderman, E.R. Zubarev, Therapeutic platforms based on gold nanoparticles and their covalent conjugates with drug molecules, Advanced drug delivery reviews, 65 (2013) 663-676.

[55] C.E. Probst, P. Zrazhevskiy, V. Bagalkot, X. Gao, Quantum dots as a platform for nanoparticle drug delivery vehicle design, Advanced drug delivery reviews, 65 (2013) 703-718.

[56] M.-L. Chen, Y.-J. He, X.-W. Chen, J.-H. Wang, Quantum-dot-conjugated graphene as a probe for simultaneous cancer-targeted fluorescent imaging, tracking, and monitoring drug delivery, Bioconjugate chemistry, 24 (2013) 387-397.

[57] B.S. Wong, S.L. Yoong, A. Jagusiak, T. Panczyk, H.K. Ho, W.H. Ang, G. Pastorin, Carbon nanotubes for delivery of small molecule drugs, Advanced drug delivery reviews, 65 (2013) 1964-2015.

[58] N.K. Mehra, V. Mishra, N. Jain, A review of ligand tethered surface engineered carbon nanotubes, Biomaterials, 35 (2014) 1267-1283.

[59] R. Juliano, Nanomedicine: is the wave cresting?, Nature Reviews Drug Discovery, 12 (2013) 171-172.

[60] M.L. Etheridge, S.A. Campbell, A.G. Erdman, C.L. Haynes, S.M. Wolf, J. McCullough, The big picture on nanomedicine: the state of investigational and approved nanomedicine products, Nanomedicine: nanotechnology, biology and medicine, 9 (2013) 1-14.

[61] W. Ulbrich, A. Lamprecht, Targeted drug-delivery approaches by nanoparticulate carriers in the therapy of inflammatory diseases, Journal of The Royal Society Interface, (2009) rsif20090285.

[62] S. Jain, A.S. Doshi, A.K. Iyer, M.M. Amiji, Multifunctional nanoparticles for targeting cancer and inflammatory diseases, Journal of drug targeting, 21 (2013) 888-903.

[63] N.K. Jain, V. Mishra, N.K. Mehra, Targeted drug delivery to macrophages, Expert opinion on drug delivery, 10 (2013) 353-367.

[64] A. Singh, M. Talekar, A. Raikar, M. Amiji, Macrophage-targeted delivery systems for nucleic acid therapy of inflammatory diseases, Journal of Controlled Release, 190 (2014) 515-530.

[65] A.K. Azad, M.V. Rajaram, L.S. Schlesinger, Exploitation of the macrophage mannose receptor (CD206) in infectious disease diagnostics and therapeutics, Journal of cytology \& molecular biology, 1 (2014).

[66] S. Put, S. Schoonooghe, N. Devoogdt, E. Schurgers, A. Avau, T. Mitera, M. D’Huyvetter, P. De Baetselier, G. Raes, T. Lahoutte, SPECT imaging of joint inflammation with Nanobodies targeting the macrophage mannose receptor in a mouse model for rheumatoid arthritis, Journal of Nuclear Medicine, 54 (2013) 807-814.

[67] D.H. Madsen, D. Leonard, A. Masedunskas, A. Moyer, H.J. Jürgensen, D.E. Peters, P. Amornphimoltham, A. Selvaraj, S.S. Yamada, D.A. Brenner, M2-like macrophages are responsible for collagen degradation through a mannose receptor-mediated pathway, The Journal of cell biology, 202 (2013) 951-966.

[68] J. Gao, P. Chen, Y. Singh, X. Zhang, Z. Szekely, S. Stein, P.J. Sinko, Novel monodisperse PEGtide dendrons: design, fabrication, and evaluation of mannose receptor-mediated macrophage targeting, Bioconjugate chemistry, 24 (2013) 1332-1344.

[69] A. Etzerodt, M.B. Maniecki, J.H. Graversen, H.J. Møller, V.P. Torchilin, S.K. Moestrup, Efficient intracellular drug-targeting of macrophages using stealth liposomes directed to the hemoglobin scavenger receptor CD163, Journal of controlled release, 160 (2012) 72-80. 
[70] L.K. Petersen, A.W. York, D.R. Lewis, S. Ahuja, K.E. Uhrich, R.K. Prud'homme, P.V. Moghe, Amphiphilic nanoparticles repress macrophage atherogenesis: novel core/shell designs for scavenger receptor targeting and down-regulation, Molecular pharmaceutics, 11 (2014) 2815-2824.

[71] M.P. Plebanek, R.K. Mutharasan, O. Volpert, A. Matov, J.C. Gatlin, C.S. Thaxton, Nanoparticle targeting and cholesterol flux through scavenger receptor type B-1 inhibits cellular exosome uptake, Scientific reports, 5 (2015).

[72] F.M. Segers, B. den Adel, I. Bot, L.M. van der Graaf, E.P. van der Veer, W. Gonzalez, I. Raynal, M. de Winther, W.K. Wodzig, R.E. Poelmann, Scavenger receptor-AI-targeted iron oxide nanoparticles for in vivo MRI detection of atherosclerotic lesions, Arteriosclerosis, thrombosis, and vascular biology, 33 (2013) 1812-1819.

[73] S. Pennathur, K. Pasichnyk, N.M. Bahrami, L. Zeng, M. Febbraio, I. Yamaguchi, D.M. Okamura, The macrophage phagocytic receptor CD36 promotes fibrogenic pathways on removal of apoptotic cells during chronic kidney injury, The American journal of pathology, 185 (2015) 2232-2245.

[74] M. Liu, F. Luo, C. Ding, S. Albeituni, X. Hu, Y. Ma, Y. Cai, L. McNally, M.A. Sanders, D. Jain, Dectin-1 Activation by a Natural Product $\beta$-Glucan Converts Immunosuppressive Macrophages into an M1-like Phenotype, The Journal of Immunology, 195 (2015) 5055-5065.

[75] F.V. Loures, E.F. Araújo, C. Feriotti, S.B. Bazan, T.A. Costa, G.D. Brown, V.L. Calich, Dectin-1 induces M1 macrophages and prominent expansion of CD8+ IL-17+ cells in pulmonary Paracoccidioidomycosis, Journal of Infectious Diseases, 210 (2014) 762-773.

[76] T. Öhman, L. Teirilä, A.-M. Lahesmaa-Korpinen, W. Cypryk, V. Veckman, S. Saijo, H. Wolff, S. Hautaniemi, T.A. Nyman, S. Matikainen, Dectin-1 pathway activates robust autophagy-dependent unconventional protein secretion in human macrophages, The Journal of Immunology, 192 (2014) 5952-5962.

[77] D. Ai, H. Jiang, M. Westerterp, A.J. Murphy, M. Wang, A. Ganda, S. Abramowicz, C. Welch, F. Almazan, Y. Zhu, Disruption of mammalian target of rapamycin complex 1 in macrophages decreases chemokine gene expression and atherosclerosis, Circulation research, 114 (2014) 1576-1584.

[78] S. Jain, M. Amiji, Tuftsin-modified alginate nanoparticles as a noncondensing macrophage-targeted DNA delivery system, Biomacromolecules, 13 (2012) 1074-1085.

[79] S.K. Tripathi, R. Goyal, M.P. Kashyap, A.B. Pant, W. Haq, P. Kumar, K.C. Gupta, Depolymerized chitosans functionalized with bPEI as carriers of nucleic acids and tuftsin-tethered conjugate for macrophage targeting, Biomaterials, 33 (2012) 4204-4219.

[80] T.-H. Tran, R. Rastogi, J. Shelke, M.M. Amiji, Modulation of macrophage functional polarity towards antiinflammatory phenotype with plasmid DNA delivery in CD44 targeting hyaluronic acid nanoparticles, Scientific reports, 5 (2015).

[81] D. Maisel, F. Birzele, E. Voss, A. Nopora, S. Bader, T. Friess, B. Goller, D. Laifenfeld, S. Weigand, V. Runza, Targeting Tumor Cells with Anti-CD44 Antibody Triggers Macrophage-Mediated Immune Modulatory Effects in a Cancer Xenograft Model, PloS one, 11 (2016) e0159716.

[82] T.L. Nascimento, H. Hillaireau, J. Vergnaud, E. Fattal, Lipid-based nanosystems for CD44 targeting in cancer treatment: recent significant advances, ongoing challenges and unmet needs, Nanomedicine, 11 (2016) 1865-1887.

[83] W. Han, R. Zaynagetdinov, F.E. Yull, V.V. Polosukhin, L.A. Gleaves, H. Tanjore, L.R. Young, T.E. Peterson, H.C. Manning, L.S. Prince, Molecular Imaging of Folate Receptor $\beta$-Positive Macrophages during Acute Lung Inflammation, American journal of respiratory cell and molecular biology, 53 (2015) 50-59.

[84] M.J. Hansen, N.A. Bandara, P.S. Low, Folate receptor expression on murine and human adipose tissue macrophages, Inflammation Research, 64 (2015) 697-706.

[85] Y. Hattori, J. Yamashita, C. Sakaida, K. Kawano, E. Yonemochi, Evaluation of antitumor effect of zoledronic acid entrapped in folate-linked liposome for targeting to tumor-associated macrophages, Journal of liposome research, 25 (2015) 131-140.

[86] L.E. Kelderhouse, S. Mahalingam, P.S. Low, Predicting Response to Therapy for Autoimmune and Inflammatory Diseases Using a Folate Receptor-Targeted Near-Infrared Fluorescent Imaging Agent, Molecular Imaging and Biology, 18 (2016) 201-208. 
[87] V. Bagalkot, M.A. Badgeley, T. Kampfrath, J.A. Deiuliis, S. Rajagopalan, A. Maiseyeu, Hybrid nanoparticles improve targeting to inflammatory macrophages through phagocytic signals, Journal of Controlled Release, 217 (2015) 243-255.

[88] H. Hosseini, Y. Li, P. Kanellakis, C. Tay, A. Cao, P. Tipping, A. Bobik, B.-H. Toh, T. Kyaw, Phosphatidylserine liposomes mimic apoptotic cells to attenuate atherosclerosis by expanding polyreactive IgM producing B1a lymphocytes, Cardiovascular research, 106 (2015) 443-452.

[89] H. Cao, Z. Dan, X. He, Z. Zhang, H. Yu, Q. Yin, Y. Li, Liposomes Coated with Isolated Macrophage Membrane Can Target Lung Metastasis of Breast Cancer, ACS nano, (2016).

[90] M. Cieslewicz, J. Tang, L.Y. Jonathan, H. Cao, M. Zavaljevski, K. Motoyama, A. Lieber, E.W. Raines, S.H. Pun, Targeted delivery of proapoptotic peptides to tumor-associated macrophages improves survival, Proceedings of the National Academy of Sciences, 110 (2013) 15919-15924.

[91] O.R. Colegio, N.-Q. Chu, A.L. Szabo, T. Chu, A.M. Rhebergen, V. Jairam, N. Cyrus, C.E. Brokowski, S.C. Eisenbarth, G.M. Phillips, Functional polarization of tumour-associated macrophages by tumour-derived lactic acid, Nature, 513 (2014) 559-563.

[92] C. Ngambenjawong, H.H. Gustafson, J.M. Pineda, N.A. Kacherovsky, M. Cieslewicz, S.H. Pun, Serum Stability and Affinity Optimization of an M2 Macrophage-Targeting Peptide (M2pep), Theranostics, 6 (2016) 1403.

[93] C.H. Ries, M.A. Cannarile, S. Hoves, J. Benz, K. Wartha, V. Runza, F. Rey-Giraud, L.P. Pradel, F. Feuerhake, I. Klaman, Targeting tumor-associated macrophages with anti-CSF-1R antibody reveals a strategy for cancer therapy, Cancer cell, 25 (2014) 846-859.

[94] G. Courties, M. Baron, J. Presumey, V. Escriou, P. van Lent, D. Scherman, A. Cantagrel, W. van den Berg, C. Jorgensen, F. Apparailly, Cytosolic phospholipase A2 $\alpha$ gene silencing in the myeloid lineage alters development of Th1 responses and reduces disease severity in collagen - induced arthritis, Arthritis \& Rheumatism, 63 (2011) 681-690.

[95] C.M. Paulos, M.J. Turk, G.J. Breur, P.S. Low, Folate receptor-mediated targeting of therapeutic and imaging agents to activated macrophages in rheumatoid arthritis, Advanced drug delivery reviews, 56 (2004) 1205-1217.

[96] S. Jain, T.-H. Tran, M. Amiji, Macrophage repolarization with targeted alginate nanoparticles containing IL10 plasmid DNA for the treatment of experimental arthritis, Biomaterials, 61 (2015) 162-177.

[97] V.V. Sumbayev, I.M. Yasinska, C.P. Garcia, D. Gilliland, G.S. Lall, B.F. Gibbs, D.R. Bonsall, L. Varani, F. Rossi, L. Calzolai, Gold Nanoparticles Downregulate Interleukin - $1 \beta$ - Induced Pro - Inflammatory Responses, Small, 9 (2013) 472-477.

[98] Z. Huang, J. Gan, L. Jia, G. Guo, C. Wang, Y. Zang, Z. Ding, J. Chen, J. Zhang, L. Dong, An orally administrated nucleotide-delivery vehicle targeting colonic macrophages for the treatment of inflammatory bowel disease, Biomaterials, 48 (2015) 26-36.

[99] H. Laroui, A.L. Theiss, Y. Yan, G. Dalmasso, H.T. Nguyen, S.V. Sitaraman, D. Merlin, Functional TNF $\alpha$ gene silencing mediated by polyethyleneimine/TNF $\alpha$ siRNA nanocomplexes in inflamed colon, Biomaterials, 32 (2011) 1218-1228.

[100] B. Xiao, H. Laroui, S. Ayyadurai, E. Viennois, M.A. Charania, Y. Zhang, D. Merlin, Mannosylated bioreducible nanoparticle-mediated macrophage-specific TNF- $\alpha$ RNA interference for IBD therapy, Biomaterials, 34 (2013) 7471-7482.

[101] J. Zhang, C. Tang, C. Yin, Galactosylated trimethyl chitosan-cysteine nanoparticles loaded with Map4k4 siRNA for targeting activated macrophages, Biomaterials, 34 (2013) 3667-3677.

[102] K. Di Gregoli, N. Jenkins, R. Salter, S. White, A.C. Newby, J.L. Johnson, MicroRNA-24 regulates macrophage behavior and retards atherosclerosis, Arteriosclerosis, thrombosis, and vascular biology, 34 (2014) 1990-2000.

[103] M.A. Hoeksema, M.J. Gijbels, J. Van den Bossche, S. van der Velden, A. Sijm, A.E. Neele, T. Seijkens, J.L. Stöger, S. Meiler, M.C. Boshuizen, Targeting macrophage Histone deacetylase 3 stabilizes atherosclerotic lesions, EMBO molecular medicine, 6 (2014) 1124-1132.

[104] S. Nakashiro, T. Matoba, R. Umezu, J.-i. Koga, M. Tokutome, S. Katsuki, K. Nakano, K. Sunagawa, K. Egashira, Pioglitazone-Incorporated Nanoparticles Prevent Plaque Destabilization and Rupture by Regulating 
Monocyte/Macrophage Differentiation in ApoE-/- Mice, Arteriosclerosis, thrombosis, and vascular biology, 36 (2016) 491-500.

[105] D.R. Lewis, L.K. Petersen, A.W. York, K.R. Zablocki, L.B. Joseph, V. Kholodovych, R.K. Prud'homme, K.E. Uhrich, P.V. Moghe, Sugar-based amphiphilic nanoparticles arrest atherosclerosis in vivo, Proceedings of the National Academy of Sciences, 112 (2015) 2693-2698.

[106] J. Tang, M.E. Lobatto, L. Hassing, S. van der Staay, S.M. van Rijs, C. Calcagno, M.S. Braza, S. Baxter, F. Fay, B.L. Sanchez-Gaytan, Inhibiting macrophage proliferation suppresses atherosclerotic plaque inflammation, Science advances, 1 (2015) e1400223.

[107] M.R. Maradana, R. Thomas, B.J. O'Sullivan, Targeted delivery of curcumin for treating type 2 diabetes, Molecular nutrition \& food research, 57 (2013) 1550-1556.

[108] Y.-Z. Zhao, X. Li, C.-T. Lu, Y.-Y. Xu, H.-F. Lv, D.-D. Dai, L. Zhang, C.-Z. Sun, W. Yang, X.-K. Li, Experiment on the feasibility of using modified gelatin nanoparticles as insulin pulmonary administration system for diabetes therapy, Acta diabetologica, 49 (2012) 315-325.

[109] J.L. Gaglia, M. Harisinghani, I. Aganj, G.R. Wojtkiewicz, S. Hedgire, C. Benoist, D. Mathis, R. Weissleder, Noninvasive mapping of pancreatic inflammation in recent-onset type-1 diabetes patients, Proceedings of the National Academy of Sciences, 112 (2015) 2139-2144.

[110] D. Di Mascolo, C.J. Lyon, S. Aryal, M.R. Ramirez, J. Wang, P. Candeloro, M. Guindani, W.A. Hsueh, P. Decuzzi, Rosiglitazone-loaded nanospheres for modulating macrophage-specific inflammation in obesity, Journal of Controlled Release, 170 (2013) 460-468.

[111] L. Ma, T.-W. Liu, M.A. Wallig, I.T. Dobrucki, L.W. Dobrucki, E.R. Nelson, K.S. Swanson, A.M. Smith, Efficient Targeting of Adipose Tissue Macrophages in Obesity with Polysaccharide Nano-Carriers, ACS nano, 10 (2016) 6952-6962.

[112] M.N. Hossen, K. Kajimoto, H. Akita, M. Hyodo, H. Harashima, A comparative study between nanoparticletargeted therapeutics and bioconjugates as obesity medication, Journal of controlled release, 171 (2013) 104-112.

[113] Y. Xue, X. Xu, X.-Q. Zhang, O.C. Farokhzad, R. Langer, Preventing diet-induced obesity in mice by adipose tissue transformation and angiogenesis using targeted nanoparticles, Proceedings of the National Academy of Sciences, 113 (2016) 5552-5557.

[114] W. Li, Q. Wang, Y. Li, F. Yu, Q. Liu, B. Qin, L. Xie, L. Lu, S. Jiang, A Nanoparticle-Encapsulated NonNucleoside Reverse-Transcriptase Inhibitor with Enhanced Anti-HIV-1 Activity and Prolonged Circulation Time in Plasma, Current pharmaceutical design, 21 (2015) 925-935.

[115] L. Wan, S. Pooyan, P. Hu, M.J. Leibowitz, S. Stein, P.J. Sinko, Peritoneal macrophage uptake, pharmacokinetics and biodistribution of macrophage-targeted PEG-fMLF (N-formyl-methionyl-leucylphenylalanine) nanocarriers for improving HIV drug delivery, Pharmaceutical research, 24 (2007) 2110-2119.

[116] M.S. McGrath, X. Jin, T. Burdo, K. Williams, ST106 Macrophage targeted therapy for AIDS: Regulation of monocyte differentiation with PA300, a novel oral form of MGBG that reverses CNS and myocardial disease in a SIV model, JAIDS Journal of Acquired Immune Deficiency Syndromes, 62 (2013) 66.

[117] H. Kutscher, F. Makita-Chingombe, S. DiTursi, Macrophage targeted nanoparticles for antiretroviral (ARV) delivery, J. Pers. Nanomed, (2015).

[118] M.A. Cannarile, C.H. Ries, S. Hoves, D. Rüttinger, Targeting tumor-associated macrophages in cancer therapy and understanding their complexity, OncoImmunology, 3 (2014) e955356.

[119] R. Noy, J.W. Pollard, Tumor-associated macrophages: from mechanisms to therapy, Immunity, 41 (2014) 49-61.

[120] M. Jinushi, Y. Komohara, Tumor-associated macrophages as an emerging target against tumors: Creating a new path from bench to bedside, Biochimica et Biophysica Acta (BBA)-Reviews on Cancer, 1855 (2015) 123130.

[121] J.W. Pollard, Tumour-educated macrophages promote tumour progression and metastasis, Nature Reviews Cancer, 4 (2004) 71-78.

[122] S. Kuhn, J. Yang, F. Ronchese, Monocyte-Derived Dendritic Cells Are Essential for CD8+ T Cell Activation and Antitumor Responses After Local Immunotherapy, Frontiers in immunology, 6 (2015).

[123] G. Marelli, P. Allavena, M. Erreni, Tumor-associated macrophages, multi-tasking cells in the cancer landscape, Cancer Res Frontiers, 1 (2015) 149-161. 
[124] A. Mantovani, P. Allavena, The interaction of anticancer therapies with tumor-associated macrophages, The Journal of experimental medicine, 212 (2015) 435-445.

[125] X. Tang, C. Mo, Y. Wang, D. Wei, H. Xiao, Anti - tumour strategies aiming to target tumour - associated macrophages, Immunology, 138 (2013) 93-104.

[126] T. Chanmee, P. Ontong, K. Konno, N. Itano, Tumor-associated macrophages as major players in the tumor microenvironment, Cancers, 6 (2014) 1670-1690.

[127] X. Tang, Tumor-associated macrophages as potential diagnostic and prognostic biomarkers in breast cancer, Cancer letters, 332 (2013) 3-10.

[128] A. Ryan, A. Colleran, A. O'Gorman, L. O'Flynn, J. Pindjacova, P. Lohan, G. O'Malley, M. Nosov, C. Mureau, L. Egan, Targeting colon cancer cell NF- $\kappa$ B promotes an anti-tumour M1-like macrophage phenotype and inhibits peritoneal metastasis, Oncogene, 34 (2015) 1563-1574.

[129] M.L. Squadrito, M. de Palma, DICERing macrophages for reprogramming TAMs, Cell Cycle, (2016) 00-00. [130] R. Pal, B. Chakraborty, A. Nath, L.M. Singh, M. Ali, D.S. Rahman, S.K. Ghosh, A. Basu, S. Bhattacharya, R. Baral, Noble metal nanoparticle-induced oxidative stress modulates tumor associated macrophages (TAMs) from an M2 to M1 phenotype: An in vitro approach, International Immunopharmacology, 38 (2016) 332-341.

[131] M. Song, T. Liu, C. Shi, X. Zhang, X. Chen, Bioconjugated Manganese Dioxide Nanoparticles Enhance Chemotherapy Response by Priming Tumor-Associated Macrophages toward M1-like Phenotype and Attenuating Tumor Hypoxia, ACS nano, 10 (2015) 633-647.

[132] S. Zhu, M. Niu, H. O’Mary, Z. Cui, Targeting of tumor-associated macrophages made possible by PEGsheddable, mannose-modified nanoparticles, Molecular pharmaceutics, 10 (2013) 3525-3530.

[133] M. Niu, S. Valdes, Y.W. Naguib, S.D. Hursting, Z. Cui, Tumor-Associated Macrophage-Mediated Targeted Therapy of Triple-Negative Breast Cancer, Molecular pharmaceutics, (2016).

[134] R. James, O.S. Manoukian, S.G. Kumbar, Poly (lactic acid) for delivery of bioactive macromolecules, Advanced Drug Delivery Reviews, (2016).

[135] N. Kamran, M. Candolfi, G.J. Baker, M.M. Ayala, M. Dzaman, P.R. Lowenstein, M.G. Castro, Gene therapy for the treatment of neurological disorders: central nervous system neoplasms, Gene Therapy for Neurological Disorders: Methods and Protocols, (2016) 467-482.

[136] L. Naldini, Gene therapy returns to centre stage, Nature, 526 (2015) 351-360.

[137] C.-H. Wu, C. Cao, J.H. Kim, C.-H. Hsu, H.J. Wanebo, W.D. Bowen, J. Xu, J. Marshall, Trojan-horse nanotube on-command intracellular drug delivery, Nano letters, 12 (2012) 5475-5480.

[138] M. Xuan, J. Shao, L. Dai, Q. He, J. Li, Macrophage cell membrane camouflaged mesoporous silica nanocapsules for in vivo cancer therapy, Advanced healthcare materials, 4 (2015) 1645-1652.

[139] B.T. Luk, L. Zhang, Cell membrane-camouflaged nanoparticles for drug delivery, Journal of Controlled Release, 220 (2015) 600-607.

[140] H. Ding, Y. Lv, D. Ni, J. Wang, Z. Tian, W. Wei, G. Ma, Erythrocyte membrane-coated NIR-triggered biomimetic nanovectors with programmed delivery for photodynamic therapy of cancer, Nanoscale, 7 (2015) 9806-9815.

[141] M. Xuan, J. Shao, L. Dai, J. Li, Q. He, Macrophage Cell Membrane Camouflaged Au Nanoshells for in Vivo Prolonged Circulation Life and Enhanced Cancer Photothermal Therapy, ACS applied materials \& interfaces, 8 (2016) 9610-9618.

[142] L. Xu, O.Y. Zolotarskaya, W.A. Yeudall, H. Yang, Click hybridization of immune cells and polyamidoamine dendrimers, Advanced healthcare materials, 3 (2014) 1430-1438.

[143] A.-M. Georgoudaki, K.E. Prokopec, V.F. Boura, E. Hellqvist, S. Sohn, J. Östling, R. Dahan, R.A. Harris, M. Rantalainen, D. Klevebring, Reprogramming Tumor-Associated Macrophages by Antibody Targeting Inhibits Cancer Progression and Metastasis, Cell reports, 15 (2016) 2000-2011.

[144] T. Quillard, K.J. Croce, Pathobiology and mechanisms of atherosclerosis, in: Cardiovascular Imaging, Springer, 2015, pp. 3-38.

[145] I. Tabas, G. García-Cardeña, G.K. Owens, Recent insights into the cellular biology of atherosclerosis, The Journal of cell biology, 209 (2015) 13-22.

[146] P. Libby, M. DiCarli, R. Weissleder, The vascular biology of atherosclerosis and imaging targets, Journal of Nuclear Medicine, 51 (2010) 33S-37S. 
[147] I. Tabas, K.E. Bornfeldt, Macrophage phenotype and function in different stages of atherosclerosis, Circulation research, 118 (2016) 653-667.

[148] P. Libby, Inflammation in atherosclerosis, Arteriosclerosis, thrombosis, and vascular biology, 32 (2012) 2045-2051.

[149] D. Karunakaran, M. Geoffrion, L. Wei, W. Gan, L. Richards, P. Shangari, E.M. DeKemp, R.A. Beanlands, L. Perisic, L. Maegdefessel, Targeting macrophage necroptosis for therapeutic and diagnostic interventions in atherosclerosis, Science Advances, 2 (2016) e1600224.

[150] C.S. Robbins, I. Hilgendorf, G.F. Weber, I. Theurl, Y. Iwamoto, J.-L. Figueiredo, R. Gorbatov, G.K. Sukhova, L.M. Gerhardt, D. Smyth, Local proliferation dominates lesional macrophage accumulation in atherosclerosis, Nature medicine, 19 (2013) 1166-1172.

[151] S. Bekkering, L.A. Joosten, J.W. van der Meer, M.G. Netea, N.P. Riksen, The epigenetic memory of monocytes and macrophages as a novel drug target in atherosclerosis, Clinical therapeutics, 37 (2015) 914-923.

[152] M. Westerterp, A.J. Murphy, M. Wang, T.A. Pagler, Y. Vengrenyuk, M.S. Kappus, D.J. Gorman, P.R. Nagareddy, X. Zhu, S. Abramowicz, Deficiency of ATP-binding cassette transporters A1 and G1 in macrophages increases inflammation and accelerates atherosclerosis in mice, Circulation research, 112 (2013) 1456-1465.

[153] S. Xu, B. Liu, M. Yin, M. Koroleva, M. Mastrangelo, D. Zhang, E. Fisher, Z. Jin, A novel TRPV4-specific agonist inhibits monocyte adhesion and atherosclerosis, Oncotarget, (2016).

[154] R. Duivenvoorden, J. Tang, D.P. Cormode, A.J. Mieszawska, D. Izquierdo-Garcia, C. Ozcan, M.J. Otten, N. Zaidi, M.E. Lobatto, S.M. van Rijs, A statin-loaded reconstituted high-density lipoprotein nanoparticle inhibits atherosclerotic plaque inflammation, Nature communications, 5 (2014).

[155] G. Chinetti-Gbaguidi, S. Colin, B. Staels, Macrophage subsets in atherosclerosis, Nature Reviews Cardiology, 12 (2015) 10-17.

[156] Y. Zhang, Q. Li, W.J. Welsh, P.V. Moghe, K.E. Uhrich, Micellar and structural stability of nanoscale amphiphilic polymers: Implications for anti-atherosclerotic bioactivity, Biomaterials, 84 (2016) 230-240.

[157] S. Ghosh, J. Bie, J. Wang, Q. Yuan, S.S. Ghosh, Cholesterol removal from plaques and elimination from the body: change in paradigm to reduce risk for heart disease, (2014).

[158] S. Meiler, Y. Baumer, E. Toulmin, K. Seng, W.A. Boisvert, MicroRNA 302a is a novel modulator of cholesterol homeostasis and atherosclerosis, Arteriosclerosis, thrombosis, and vascular biology, 35 (2015) 323331.

[159] N. Leitinger, I.G. Schulman, Phenotypic polarization of macrophages in atherosclerosis, Arteriosclerosis, thrombosis, and vascular biology, 33 (2013) 1120-1126.

[160] A.J. Murphy, D. Dragoljevic, A.R. Tall, Cholesterol efflux pathways regulate myelopoiesis: a potential link to altered macrophage function in atherosclerosis, M1/M2 Macrophages: The Arginine Fork in the Road to Health and Disease, (2015) 163.

[161] J. Zhang, S. Nie, R. Martinez-Zaguilan, S.R. Sennoune, S. Wang, Formulation, characteristics and antiatherogenic bioactivities of CD36-targeted epigallocatechin gallate (EGCG)-loaded nanoparticles, The Journal of nutritional biochemistry, 30 (2016) 14-23.

[162] D.R. Lewis, L.K. Petersen, A.W. York, S. Ahuja, H. Chae, L.B. Joseph, S. Rahimi, K.E. Uhrich, P.B. Haser, P.V. Moghe, Nanotherapeutics for inhibition of atherogenesis and modulation of inflammation in atherosclerotic plaques, Cardiovascular research, 109 (2016) 283-293.

[163] S. Ghosh, Q. Tang, D. Logothetis, J. Wang, Role of Cholesteryl Ester (CE) Hydrolase Mediated Mobilization of Intracellular CE in Regulating Inflammasome Activation, The FASEB Journal, 29 (2015) 715.712.

[164] P.J. Barter, K.-A. Rye, Cholesteryl Ester Transfer Protein Inhibition Is Not Yet Dead—Pro, Arteriosclerosis, thrombosis, and vascular biology, 36 (2016) 439-441.

[165] S. Ghosh, J. Wang, J. Bie, Q. Yuan, O. Zolotarskaya, H. Yang, Development of Functionalized Nanoparticle Platform for Reducing Atherosclerosis, Arteriosclerosis, Thrombosis, and Vascular Biology, 35 (2015) A13-A13.

[166] W. Annema, A. von Eckardstein, High-density lipoproteins, Circulation Journal, 77 (2013) 2432-2448.

[167] D.J. Rader, G.K. Hovingh, HDL and cardiovascular disease, The Lancet, 384 (2014) 618-625. 
[168] L. Calabresi, M. Gomaraschi, S. Simonelli, F. Bernini, G. Franceschini, HDL and atherosclerosis: Insights from inherited HDL disorders, Biochimica et Biophysica Acta (BBA)-Molecular and Cell Biology of Lipids, 1851 (2015) 13-18.

[169] S. Marrache, S. Dhar, Biodegradable synthetic high-density lipoprotein nanoparticles for atherosclerosis, Proceedings of the National Academy of Sciences, 110 (2013) 9445-9450.

[170] W. Zhang, H. He, J. Liu, J. Wang, S. Zhang, S. Zhang, Z. Wu, Pharmacokinetics and atherosclerotic lesions targeting effects of tanshinone IIA discoidal and spherical biomimetic high density lipoproteins, Biomaterials, 34 (2013) 306-319.

[171] L. Liu, H. He, M. Zhang, S. Zhang, W. Zhang, J. Liu, Hyaluronic acid-decorated reconstituted high density lipoprotein targeting atherosclerotic lesions, Biomaterials, 35 (2014) 8002-8014.

[172] J.M. Tarkin, M.R. Dweck, N.R. Evans, R.A. Takx, A.J. Brown, A. Tawakol, Z.A. Fayad, J.H. Rudd, Imaging atherosclerosis, Circulation research, 118 (2016) 750-769.

[173] E.A. Osborn, F.A. Jaffer, Imaging atherosclerosis and risk of plaque rupture, Current atherosclerosis reports, 15 (2013) 1-9.

[174] C. Tarin, M. Carril, J.L. Martin-Ventura, I. Markuerkiaga, D. Padro, P. Llamas-Granda, J.A. Moreno, I. García, N. Genicio, S. Plaza-Garcia, Targeted gold-coated iron oxide nanoparticles for CD163 detection in atherosclerosis by MRI, Scientific reports, 5 (2015).

[175] M.H. El-Dakdouki, K. El-Boubbou, M. Kamat, R. Huang, G.S. Abela, M. Kiupel, D.C. Zhu, X. Huang, CD44 targeting magnetic glyconanoparticles for atherosclerotic plaque imaging, Pharmaceutical research, 31 (2014) 1426-1437.

[176] D.G. You, G. Saravanakumar, S. Son, H.S. Han, R. Heo, K. Kim, I.C. Kwon, J.Y. Lee, J.H. Park, Dextran sulfate-coated superparamagnetic iron oxide nanoparticles as a contrast agent for atherosclerosis imaging, Carbohydrate polymers, 101 (2014) 1225-1233.

[177] B.L. Sanchez-Gaytan, F. Fay, M.E. Lobatto, J. Tang, M. Ouimet, Y. Kim, S.E. van der Staay, S.M. van Rijs, B. Priem, L. Zhang, HDL-mimetic PLGA nanoparticle to target atherosclerosis plaque macrophages, Bioconjugate chemistry, 26 (2015) 443-451.

[178] C. Perez-Medina, T. Binderup, M. Lobatto, S. Baxter, C. Calcagno, S. Ishino, T. Reiner, J. Lewis, Z. Fayad, W. Mulder, Multimodal PET imaging of high-density lipoprotein's trafficking in multiple atherosclerosis models, Journal of Nuclear Medicine, 57 (2016) 63-63.

[179] O. Veiseh, B.C. Tang, K.A. Whitehead, D.G. Anderson, R. Langer, Managing diabetes with nanomedicine: challenges and opportunities, Nature Reviews Drug Discovery, 14 (2015) 45-57.

[180] S. Nie, J. Zhang, R. Martinez-Zaguilan, S. Sennoune, M.N. Hossen, A.H. Lichtenstein, J. Cao, G.E. Meyerrose, R. Paone, S. Soontrapa, Detection of atherosclerotic lesions and intimal macrophages using CD36targeted nanovesicles, Journal of Controlled Release, 220 (2015) 61-70.

[181] R.M. Pope, Apoptosis as a therapeutic tool in rheumatoid arthritis, Nature Reviews Immunology, 2 (2002) 527-535.

[182] B. Soler Palacios, L. Estrada - Capetillo, E. Izquierdo, G. Criado, C. Nieto, C. Municio, I. González Alvaro, P. Sánchez - Mateos, J.L. Pablos, A.L. Corbí, Macrophages from the synovium of active rheumatoid arthritis exhibit an activin A - dependent pro - inflammatory profile, The Journal of pathology, 235 (2015) 515526.

[183] J.-L. Davignon, M. Hayder, M. Baron, J.-F. Boyer, A. Constantin, F. Apparailly, R. Poupot, A. Cantagrel, Targeting monocytes/macrophages in the treatment of rheumatoid arthritis, Rheumatology, 52 (2013) 590-598.

[184] J. Bondeson, The Role of Synovial Macrophages in Rheumatoid Arthritis and Osteoarthritis: Its Implications for Radiosynovectomy, in: Local Treatment of Inflammatory Joint Diseases, Springer, 2015, pp. 3148.

[185] J. Collison, Rheumatoid arthritis: Features of synovium in RA remission revealed, Nature Reviews Rheumatology, 12 (2016) 316-316.

[186] E. Nogueira, A.C. Gomes, A. Preto, A. Cavaco-Paulo, Folate-targeted nanoparticles for rheumatoid arthritis therapy, Nanomedicine: Nanotechnology, Biology and Medicine, 12 (2016) 1113-1126. 
[187] I.A. Udalova, A. Mantovani, M. Feldmann, Macrophage heterogeneity in the context of rheumatoid arthritis, Nature Reviews Rheumatology, 12 (2016) 472-485.

[188] Y. Komano, N. Yagi, T. Nanki, Joint-Targeting Drug Delivery System for Rheumatoid Arthritis: siRNA Encapsulated Liposome, Pharmaceutica Analytica Acta, 6 (2015) 1000352.

[189] Z. Jiao, W. Wang, J. Ma, S. Wang, Z. Su, H. Xu, Notch signaling mediates TNF- $\alpha$-induced IL-6 production in cultured fibroblast-like synoviocytes from rheumatoid arthritis, Clinical and Developmental Immunology, 2012 (2012) Article ID 350209.

[190] Z. Jiao, W. Wang, S. Hua, M. Liu, H. Wang, X. Wang, Y. Chen, H. Xu, L. Lu, Blockade of Notch signaling ameliorates murine collagen-induced arthritis via suppressing Th1 and Th17 cell responses, The American journal of pathology, 184 (2014) 1085-1093.

[191] M.J. Kim, J.-S. Park, S.J. Lee, J. Jang, J.S. Park, S.H. Back, G. Bahn, J.H. Park, Y.M. Kang, S.H. Kim, Notch1 targeting siRNA delivery nanoparticles for rheumatoid arthritis therapy, Journal of Controlled Release, 216 (2015) 140-148.

[192] M. Hayder, M. Poupot, M. Baron, D. Nigon, C.-O. Turrin, A.-M. Caminade, J.-P. Majoral, R.A. Eisenberg, J.-J. Fournié, A. Cantagrel, A phosphorus-based dendrimer targets inflammation and osteoclastogenesis in experimental arthritis, Science Translational Medicine, 3 (2011) 81ra35-81ra35.

[193] M.F. Neurath, Cytokines in inflammatory bowel disease, Nature Reviews Immunology, 14 (2014) 329-342.

[194] M.Z. Cader, A. Kaser, Recent advances in inflammatory bowel disease: mucosal immune cells in intestinal inflammation, Gut, 62 (2013) 1653-1664.

[195] A. Hayashi, T. Sato, N. Kamada, Y. Mikami, K. Matsuoka, T. Hisamatsu, T. Hibi, A. Roers, H. Yagita, T. Ohteki, A single strain of Clostridium butyricum induces intestinal IL-10-producing macrophages to suppress acute experimental colitis in mice, Cell host \& microbe, 13 (2013) 711-722.

[196] I. Ordás, D.R. Mould, B.G. Feagan, W.J. Sandborn, Anti - TNF monoclonal antibodies in inflammatory bowel disease: pharmacokinetics - based dosing paradigms, Clinical Pharmacology \& Therapeutics, 91 (2012) 635-646.

[197] C. Tillack, L.M. Ehmann, M. Friedrich, R.P. Laubender, P. Papay, H. Vogelsang, J. Stallhofer, F. Beigel, A. Bedynek, M. Wetzke, Anti-TNF antibody-induced psoriasiform skin lesions in patients with inflammatory bowel disease are characterised by interferon- $\gamma$-expressing Th1 cells and IL-17A/IL-22-expressing Th17 cells and respond to anti-IL-12/IL-23 antibody treatment, Gut, 63 (2014) 567-577.

[198] F. Kesisoglou, E.M. Zimmermann, Novel drug delivery strategies for the treatment of inflammatory bowel disease, Expert opinion on drug delivery, 2 (2005) 451-463.

[199] M.Y. Donath, S.E. Shoelson, Type 2 diabetes as an inflammatory disease, Nature Reviews Immunology, 11 (2011) 98-107.

[200] R.M. Pollack, M.Y. Donath, D. LeRoith, G. Leibowitz, Anti-inflammatory Agents in the Treatment of Diabetes and Its Vascular Complications, Diabetes Care, 39 (2016) S244-S252.

[201] D. Laveti, M. Kumar, R. Hemalatha, R. Sistla, V. GM Naidu, V. Talla, V. Verma, N. Kaur, R. Nagpal, Anti-inflammatory treatments for chronic diseases: a review, Inflammation \& Allergy-Drug Targets (Formerly Current Drug Targets-Inflammation \& Allergy), 12 (2013) 349-361.

[202] I. Tabas, C.K. Glass, Anti-inflammatory therapy in chronic disease: challenges and opportunities, Science, 339 (2013) 166-172.

[203] Y. Shiomi, T. Yamauchi, M. Iwabu, M. Okada-Iwabu, R. Nakayama, Y. Orikawa, Y. Yoshioka, K. Tanaka, K. Ueki, T. Kadowaki, A Novel Peroxisome Proliferator-activated Receptor (PPAR) $\alpha$ Agonist and PPAR $\gamma$ Antagonist, Z-551, Ameliorates High-fat Diet-induced Obesity and Metabolic Disorders in Mice, Journal of Biological Chemistry, 290 (2015) 14567-14581.

[204] C. Janani, B.R. Kumari, PPAR gamma gene-a review, Diabetes \& Metabolic Syndrome: Clinical Research \& Reviews, 9 (2015) 46-50.

[205] J.J. Fuster, N. Ouchi, N. Gokce, K. Walsh, Obesity-induced changes in adipose tissue microenvironment and their impact on cardiovascular disease, Circulation research, 118 (2016) 1786-1807. 
[206] E. Jeffery, A. Wing, B. Holtrup, Z. Sebo, J.L. Kaplan, R. Saavedra-Peña, C.D. Church, L. Colman, R. Berry, M.S. Rodeheffer, The adipose tissue microenvironment regulates depot-specific adipogenesis in obesity, Cell Metabolism, 24 (2016) 142-150.

[207] G. Jia, L.A. Martinez-Lemus, J.R. Sowers, Interaction of adipogenesis and angiogenesis in dietary-induced obesity, Diabetes, 64 (2015) 2326-2328.

[208] W.H. Dietz, L.A. Baur, K. Hall, R.M. Puhl, E.M. Taveras, R. Uauy, P. Kopelman, Management of obesity: improvement of health-care training and systems for prevention and care, The Lancet, 385 (2015) 2521-2533.

[209] L. Adorini, Interleukin 12 and autoimmune diabetes, Nature genetics, 27 (2001) 131-132.

[210] M.Y. Donath, Targeting inflammation in the treatment of type 2 diabetes: time to start, Nature reviews Drug discovery, 13 (2014) 465-476.

[211] A. Lehuen, J. Diana, P. Zaccone, A. Cooke, Immune cell crosstalk in type 1 diabetes, Nature Reviews Immunology, 10 (2010) 501-513.

[212] F. González-Scarano, J. Martín-García, The neuropathogenesis of AIDS, Nature Reviews Immunology, 5 (2005) 69-81.

[213] F. Hladik, M.J. McElrath, Setting the stage: host invasion by HIV, Nature Reviews Immunology, 8 (2008) 447-457.

[214] M. Swami, HIV infections: Restricting HIV from macrophages, Nature medicine, 19 (2013) 416-416.

[215] D. Rudnicka, O. Schwartz, Intrusive HIV-1-infected cells, Nature immunology, 10 (2009) 933-934.

[216] J.M. Orenstein, C. Fox, S.M. Wahl, Macrophages as a source of HIV during opportunistic infections, Science, 276 (1997) 1857-1861.

[217] R.R. Adhikary, P. More, R. Banerjee, Smart nanoparticles as targeting platforms for HIV infections, Nanoscale, 7 (2015) 7520-7534.

[218] S.D. Mahajan, R. Aalinkeel, W.-C. Law, J.L. Reynolds, B.B. Nair, D.E. Sykes, K.-T. Yong, I. Roy, P.N. Prasad, S.A. Schwartz, Anti-HIV-1 nanotherapeutics: promises and challenges for the future, Int J Nanomedicine, 7 (2012) 5301-5314.

[219] S. Ghosh, L. Mondal, S. Chakraborty, B. Mukherjee, Early Stage HIV Management and Reduction of Stavudine-Induced Hepatotoxicity in Rats by Experimentally Developed Biodegradable Nanoparticles, AAPS PharmSciTech, (2016) 1-13.

[220] J.L. Reynolds, W.C. Law, S.D. Mahajan, R. Aalinkeel, B. Nair, D.E. Sykes, K.-T. Yong, R. Hui, P.N. Prasad, S.A. Schwartz, Nanoparticle based galectin-1 gene silencing, implications in methamphetamine regulation of HIV-1 infection in monocyte derived macrophages, Journal of Neuroimmune Pharmacology, 7 (2012) 673-685. [221] T. Bronshtein, N. Toledano, D. Danino, S. Pollack, M. Machluf, Cell derived liposomes expressing CCR5 as a new targeted drug-delivery system for HIV infected cells, Journal of controlled release, 151 (2011) 139-148.

[222] P. Narayanasamy, B.L. Switzer, B.E. Britigan, Prolonged-acting, multi-targeting gallium nanoparticles potently inhibit growth of both HIV and mycobacteria in co-infected human macrophages, Scientific reports, 5 (2015) 8824. 


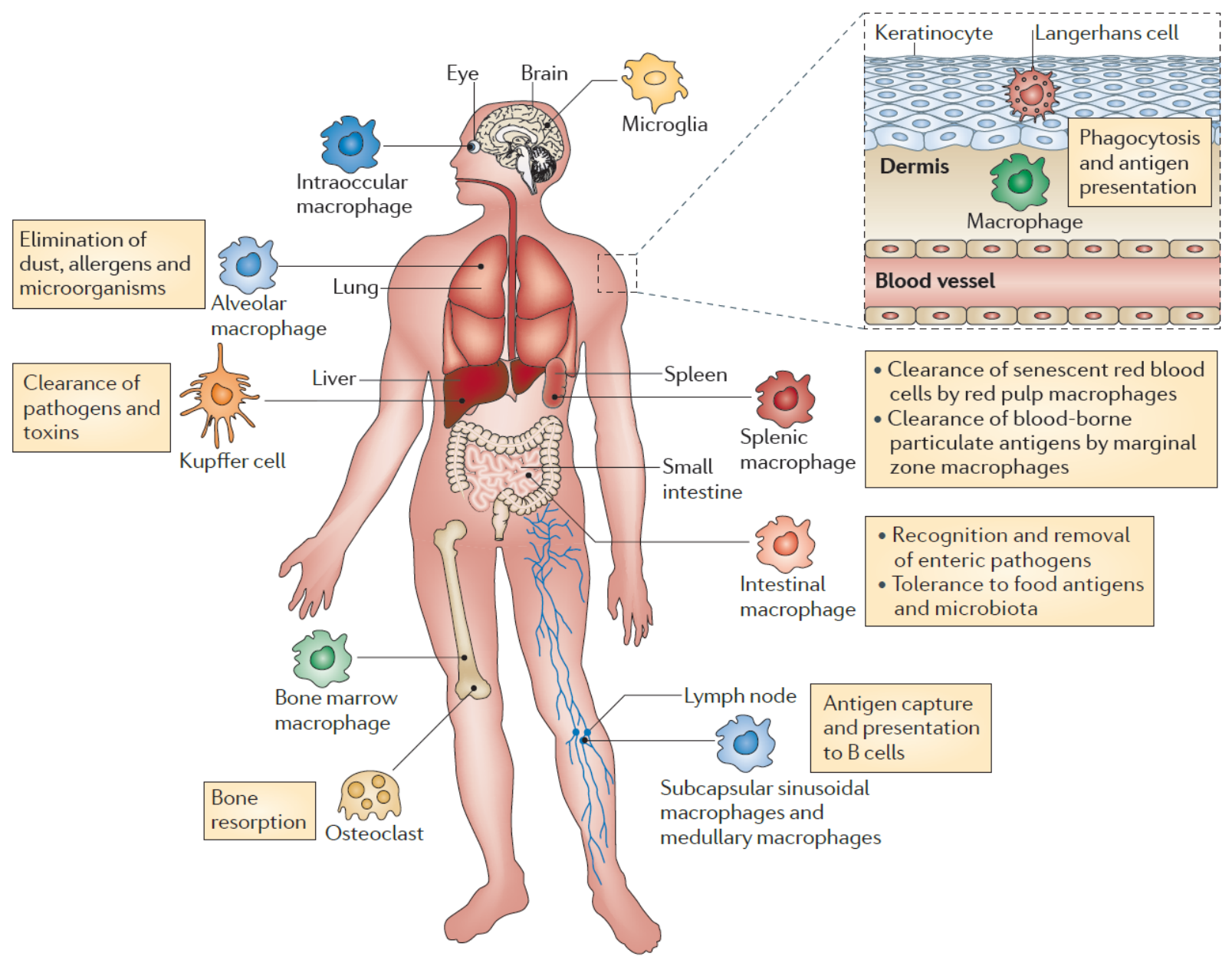

Fig. 1.Protective and pathogenic functions of macrophage subsets. Adapted with permission from [2]. 


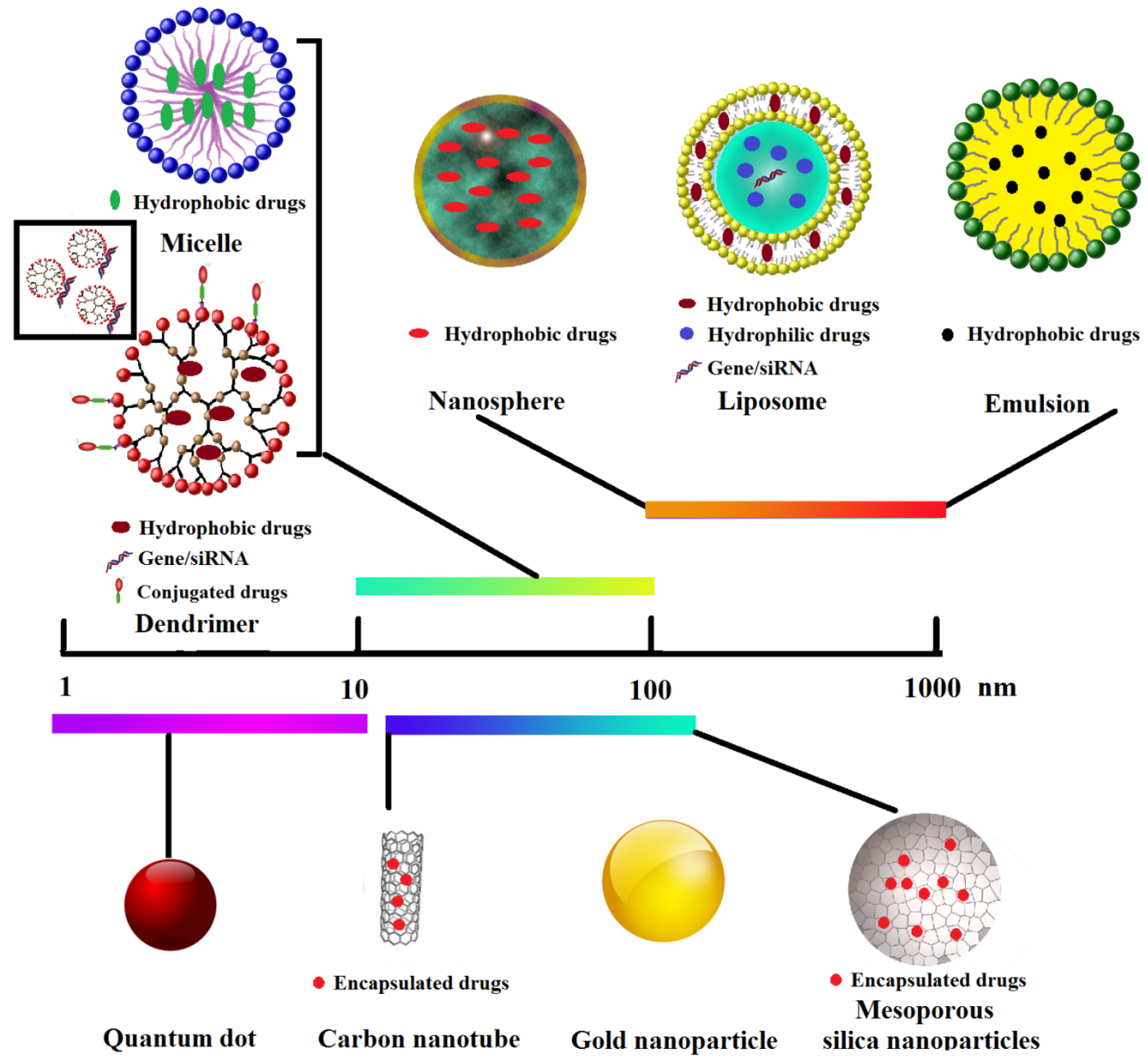

Fig. 2.Graphical illustrationof different types of nanoparticles. 


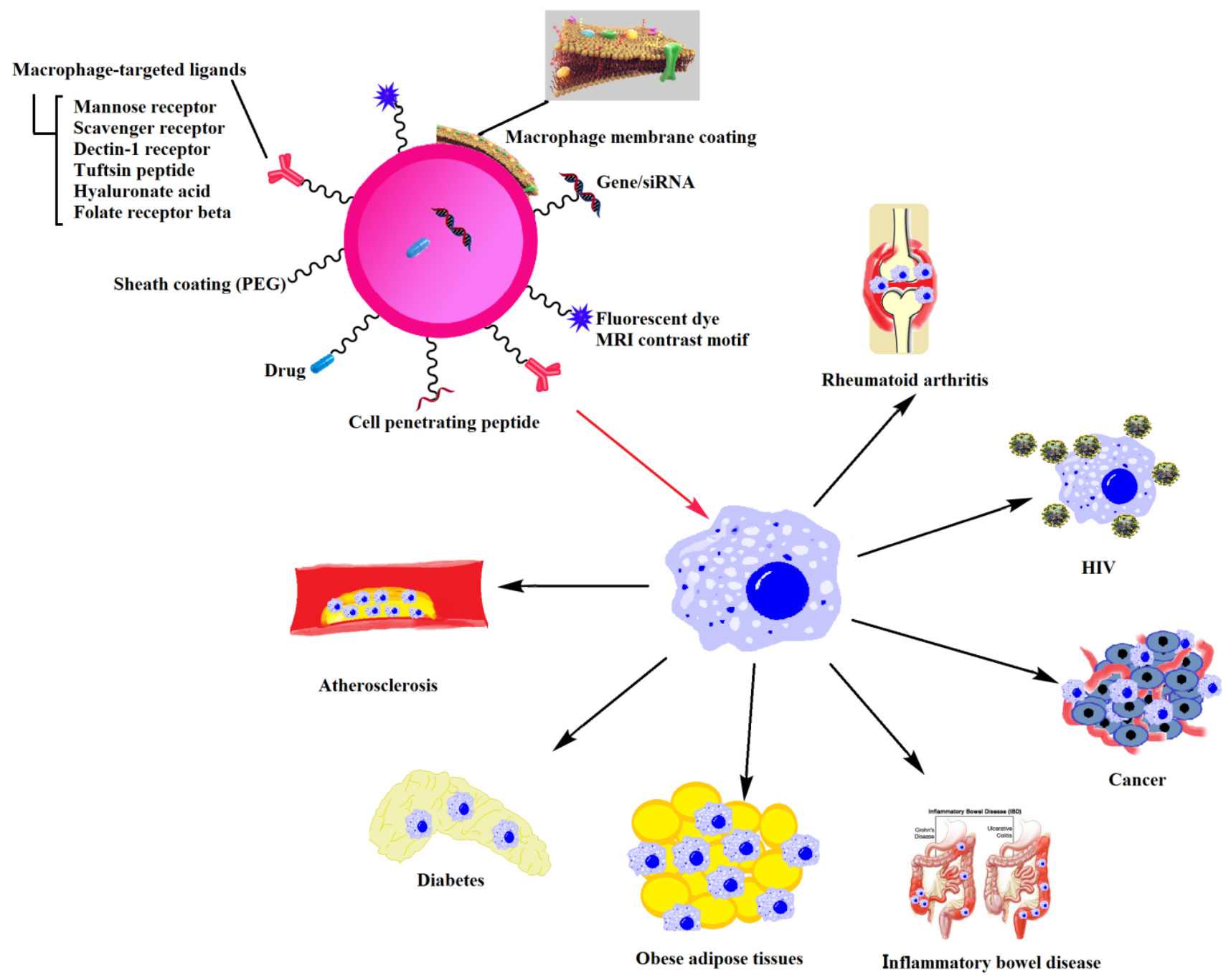

Fig. 3. Multifunctional nanomedicines targeting dysfunctional macrophages-associated diseases. 


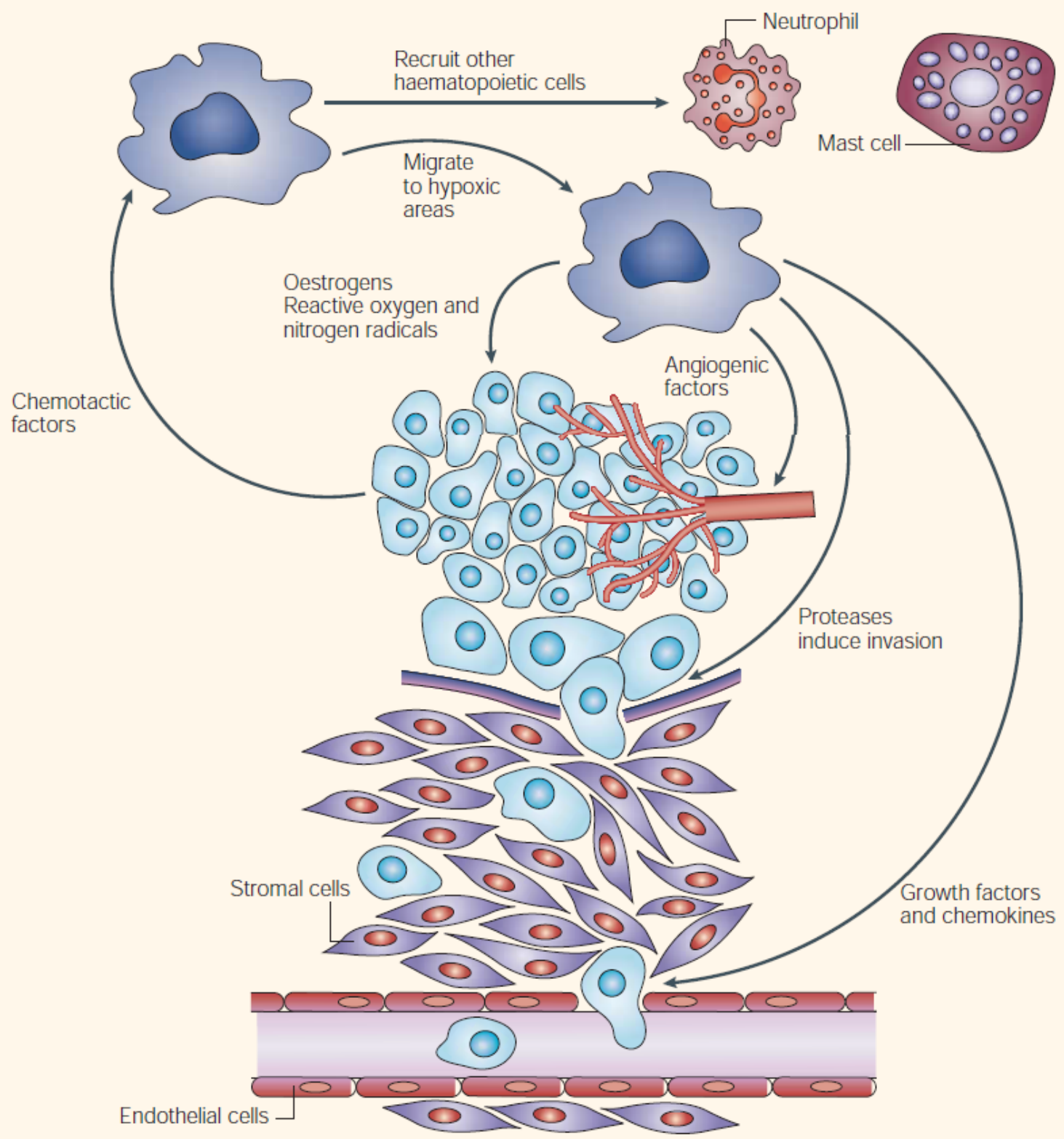

Fig 4.Pro-tumorigenic functions of tumor-associated macrophages.Adapted with permission from [121]. 


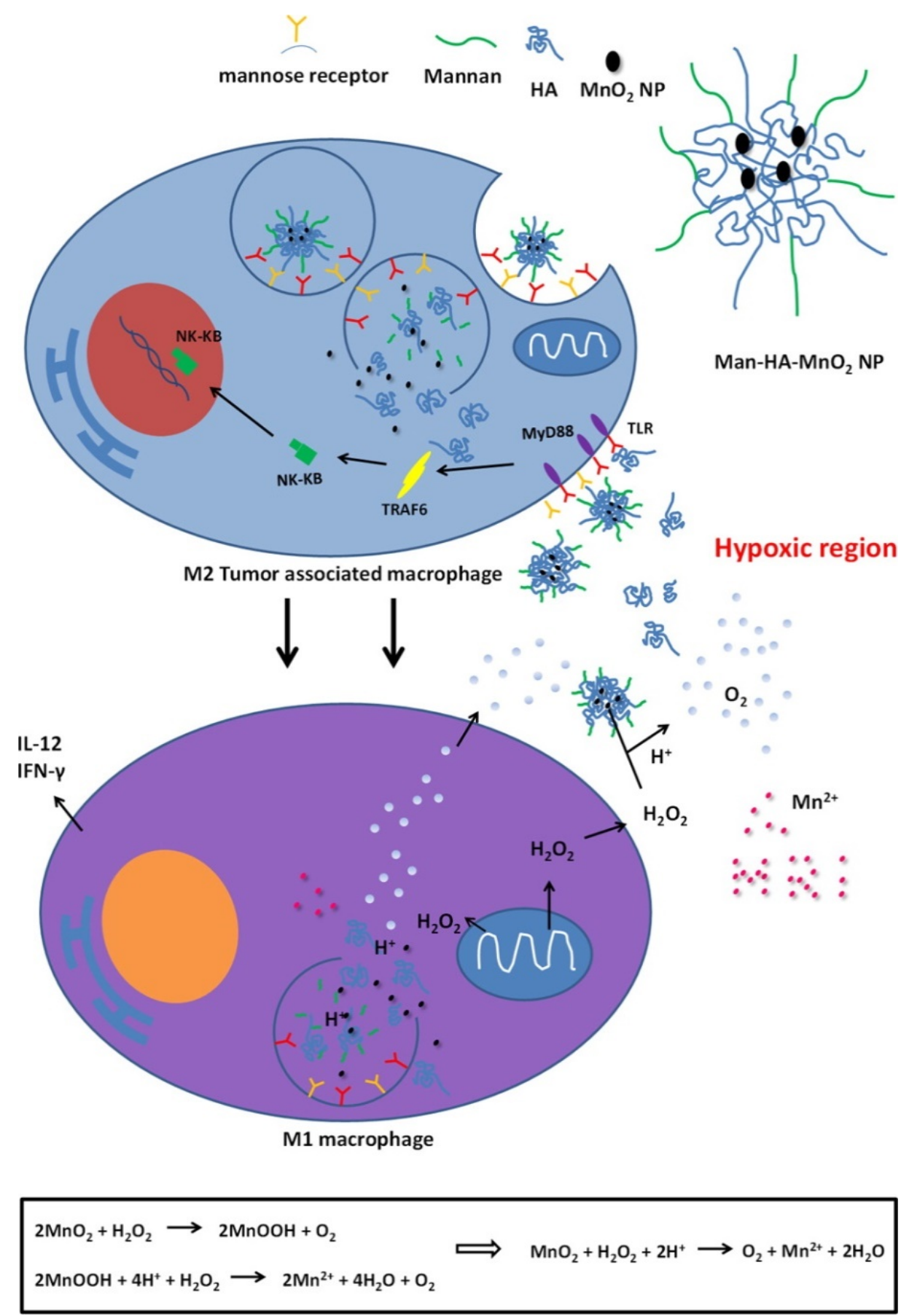

Fig. 5.Multifunctionality of Man-HA-MnO $2 ~ N P s: ~ \mathrm{MnO}_{2}$ particles ( $\left.15 \mathrm{~nm}\right)$ are entrapped in hyaluronic acid (HA) with mannan molecules attached. When Man-HA- $\mathrm{MnO}_{2} \mathrm{NPs}$ are recognized and uptaken by mannose receptor of TAMs, hyaluronic acid (HA) reprograms anti-inflammatory, pro-tumoral M2 TAMs to pro-inflammatory,

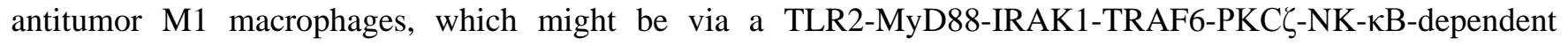
pathway. The reprogrammed M1 macrophages secrete high level of IL-12, IFN- $\gamma$ and $\mathrm{H}_{2} \mathrm{O}_{2}$. The high reactivity of $\mathrm{MnO}_{2}$ NPs toward $\mathrm{H}_{2} \mathrm{O}_{2}$ allows for the simultaneous production of $\mathrm{O}_{2}$ and $\mathrm{Mn} 2+$ ions and regulation of $\mathrm{pH}$ of tumor hypoxia. Once $\mathrm{MnO}_{2} \mathrm{NPs}$ are reduced into Mn2+ ions, they exhibit strong enhancement in both T1- and T2-weighted MRI.Adapted with permission from [131]. 
(i)

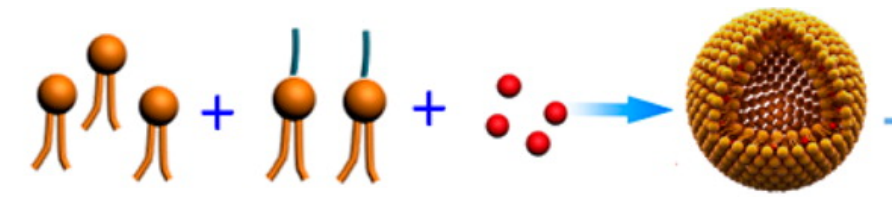

DOPE DSPE-PEG Emtansine Emtansine

(ii)

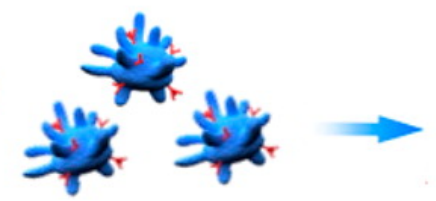

Macrophage

Macrophage membrane

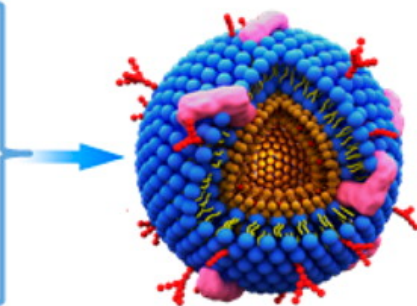

MEL

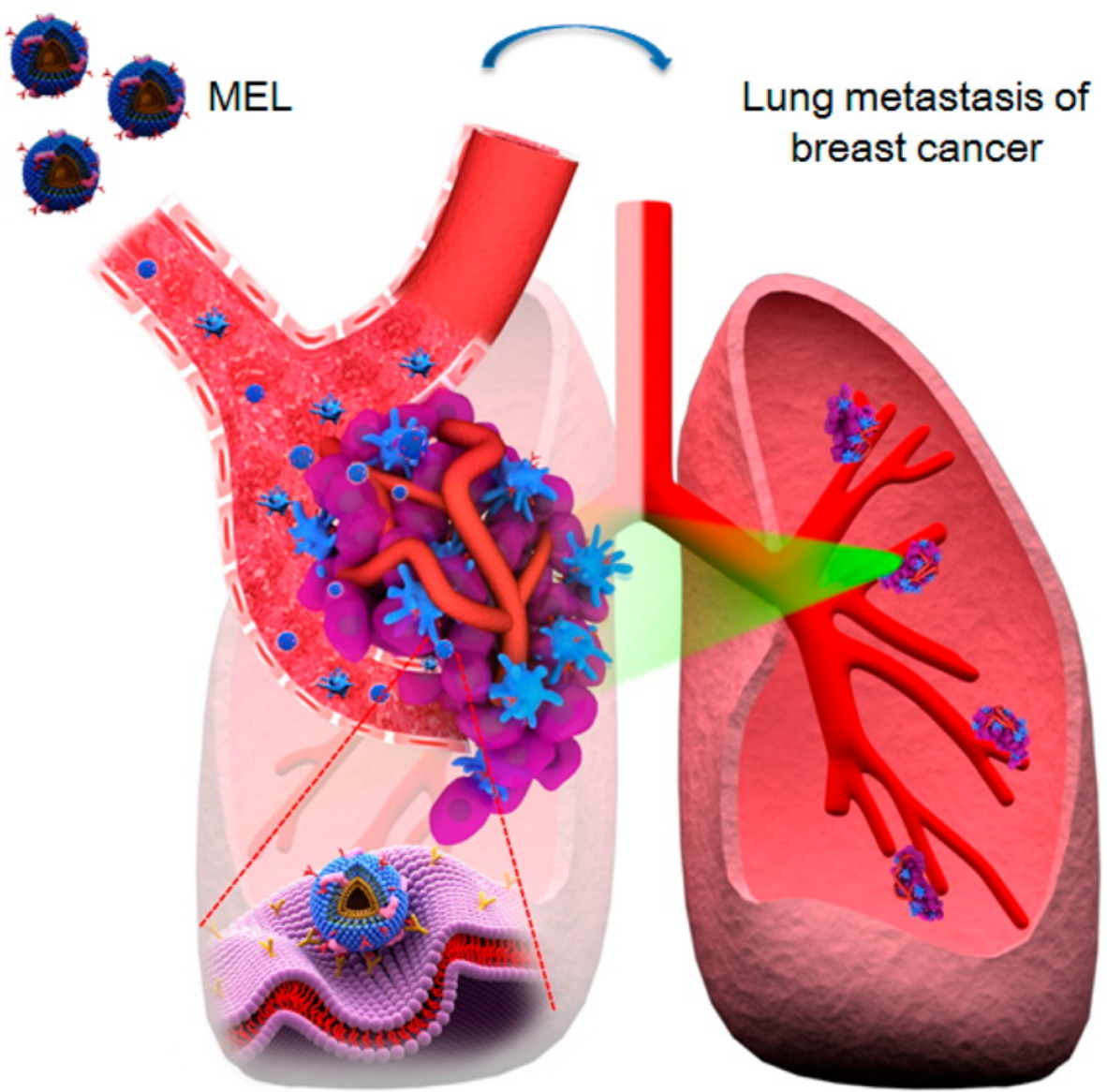

Fig 6.Left panel: Macrophage-membrane-coated emtansine liposome was fabricated by coating an emtansine liposome with anisolated macrophage membrane to confer the biomimetic functions ofthe macrophage, thereby facilitating the specific targeting to metastaticsites and enhancing the therapeutic efficacy on cancer metastasis. Adapted with permission from [89]. 


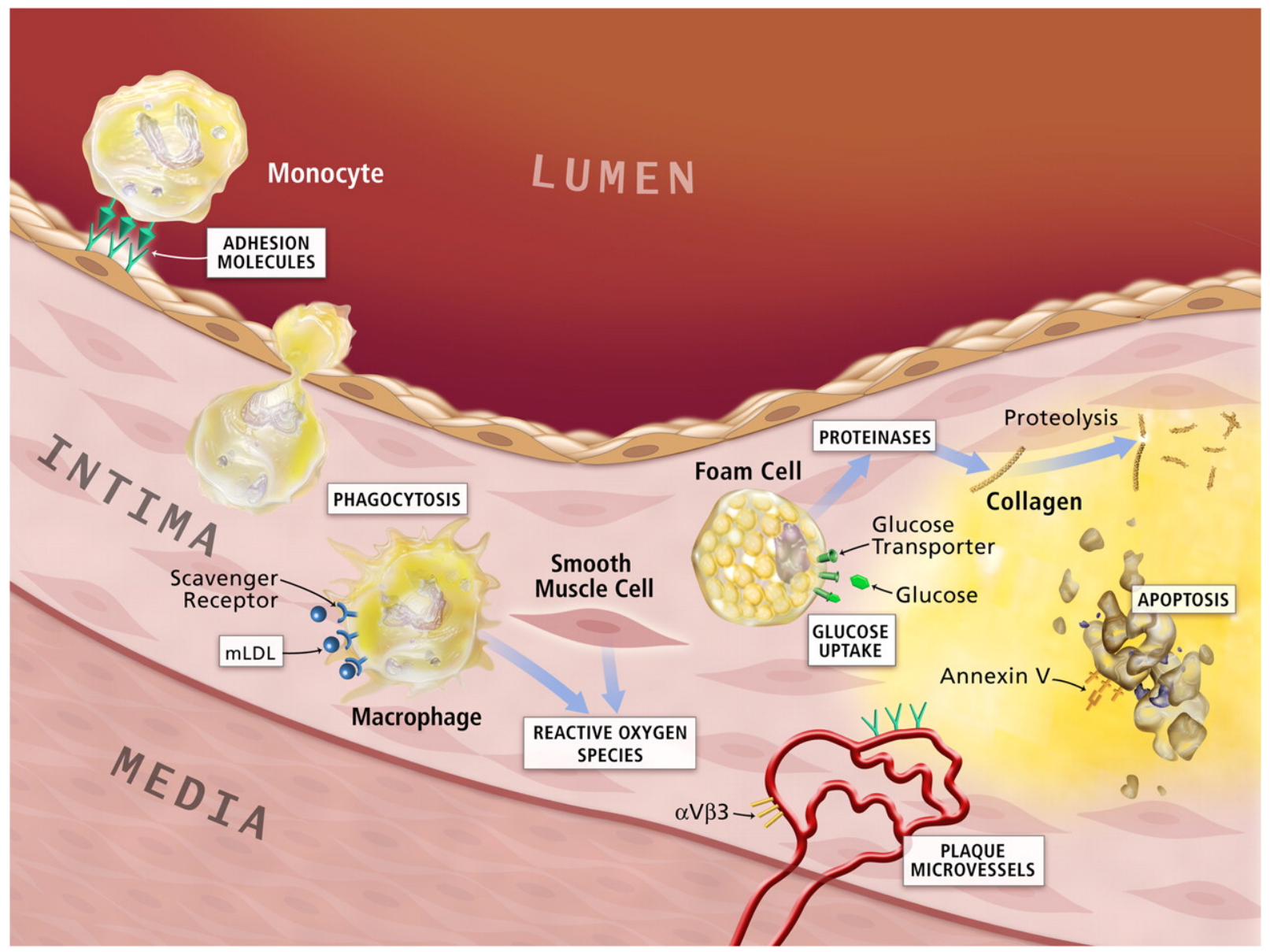

Fig. 7.Potential molecular imaging targets in atherosclerosis. White boxes show putative targets for molecular imaging of atherosclerosis. Atherogenesis involves recruitment of inflammatory cells from blood, represented by the monocyte in the upper-left-hand corner of this diagram. Monocytes are the most numerous leukocytes in atherosclerotic plaque. Recruitment depends on expression of adhesion molecules on macrovascular endothelium, as shown, and on plaque microvessels. Once resident in the arterial intima, activated macrophages become phagocytically active, a process that provides another potential target for plaque imaging. Oxidatively modified low-density lipoprotein (mLDL)-associated epitopes that accumulate in plaques may also serve as targets for molecular imaging. Foam cells may exhibit increased metabolic activity, augmenting their uptake of glucose, a process already measurable in the clinic by ${ }^{18} \mathrm{~F}$-FDG uptake. Activated phagocytes can also elaborate proteindegrading enzymes that can catabolize collagen in the plaque's fibrous cap, weakening it, and rendering it susceptible to rupture and hence thrombosis. Mononuclear phagocytes dying by apoptosis in plaques display augmented levels of phosphatidylserine on their surface. Probes for apoptosis such as annexin V may also visualize complicated atheromata. Microvessels themselves can express not only leukocyte adhesion molecules (shown in green) but also integrins such as $\alpha \mathrm{V} \beta 3$. Proof-of-principle experiments in animals support each process or molecule in white boxes as target for molecular imaging agents.Adapted with permission from [146]. 


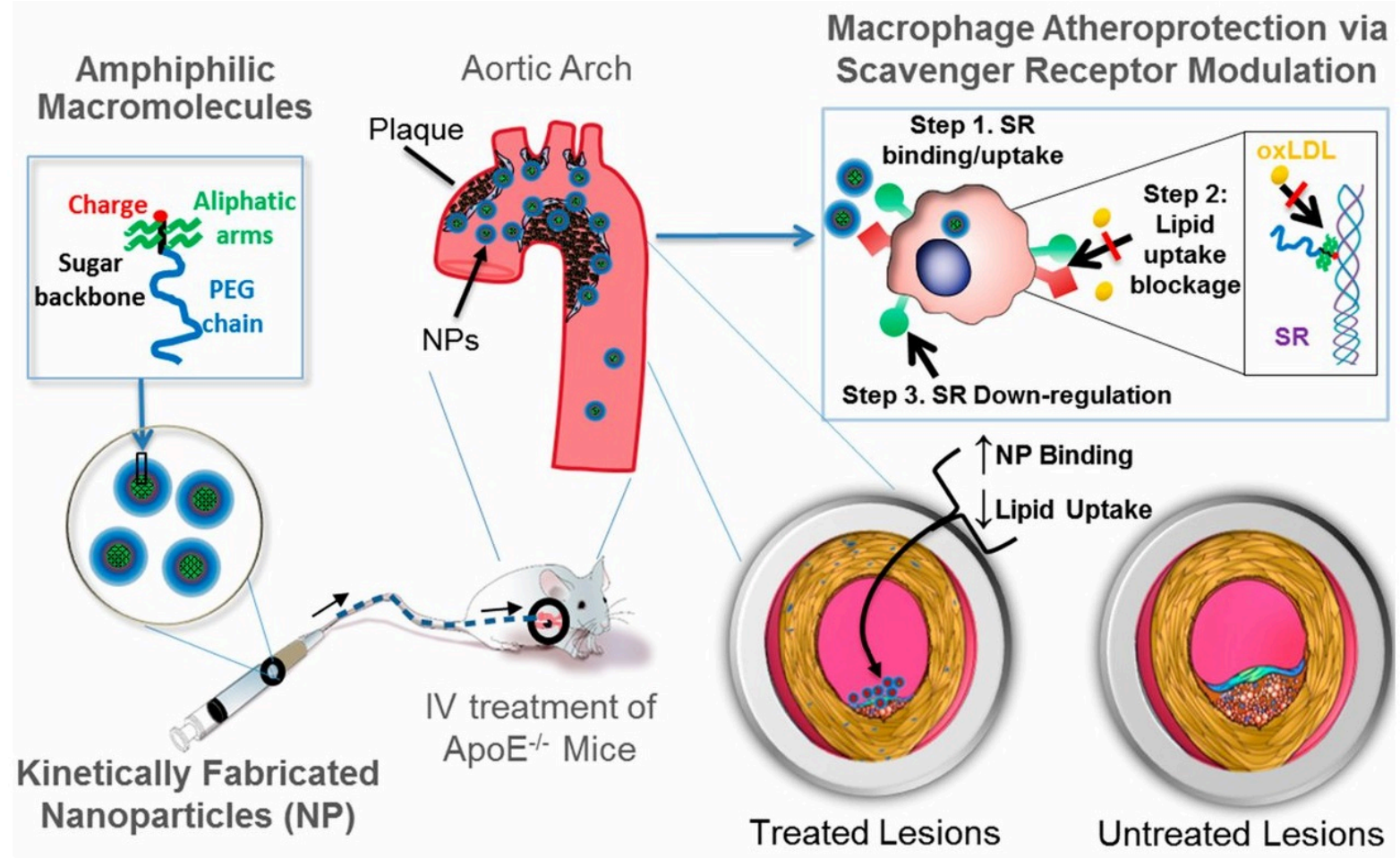

Fig. 8.The envisioned paradigm to counteract atherosclerotic plaque development aims to repress lipidscavenging receptors at the level of lesionbased macrophages. Sugar-based AMs were designed to competitively blockoxLDL uptake via binding and regulation of SRs on human macrophages.A library of AMs, with systematic variations in charge, stereochemistry, andsugar backbones, was synthesized and kinetically fabricated into serumstable, core/shell NPs and screened in vitro to identify shell architecturesthat exhibited maximal atheroprotective potency. To demonstrate lesionlevel intervention, the lead NP was administered in an atherosclerosisanimal model to challenge lesion development during coronary arterydisease.Adapted with permission from [105]. 


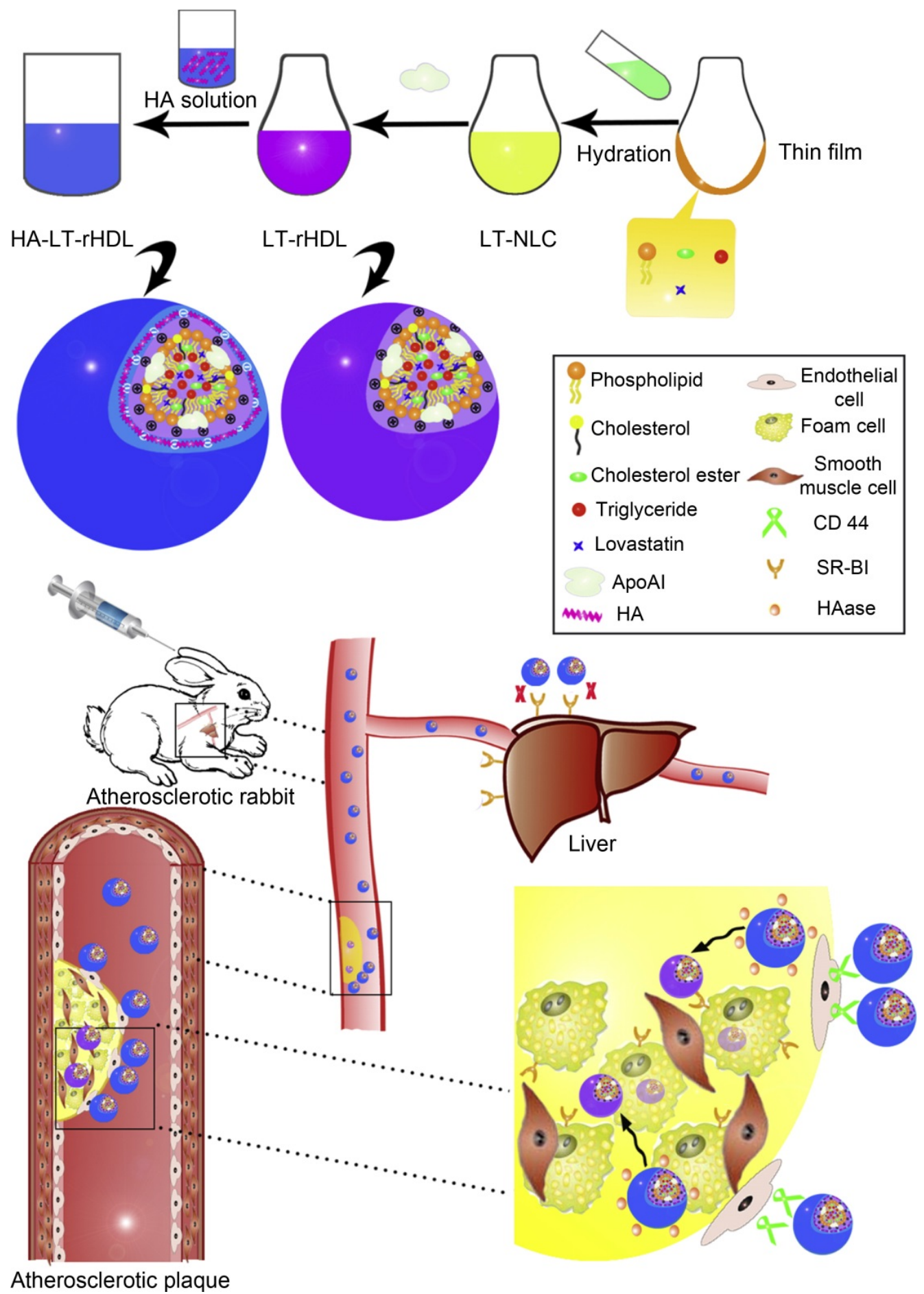

Fig. 9.Schematic diagram on preparation methods and atherosclerotic lesion targeting property of HA-LTrHDL.Adapted with permission from [171]. 


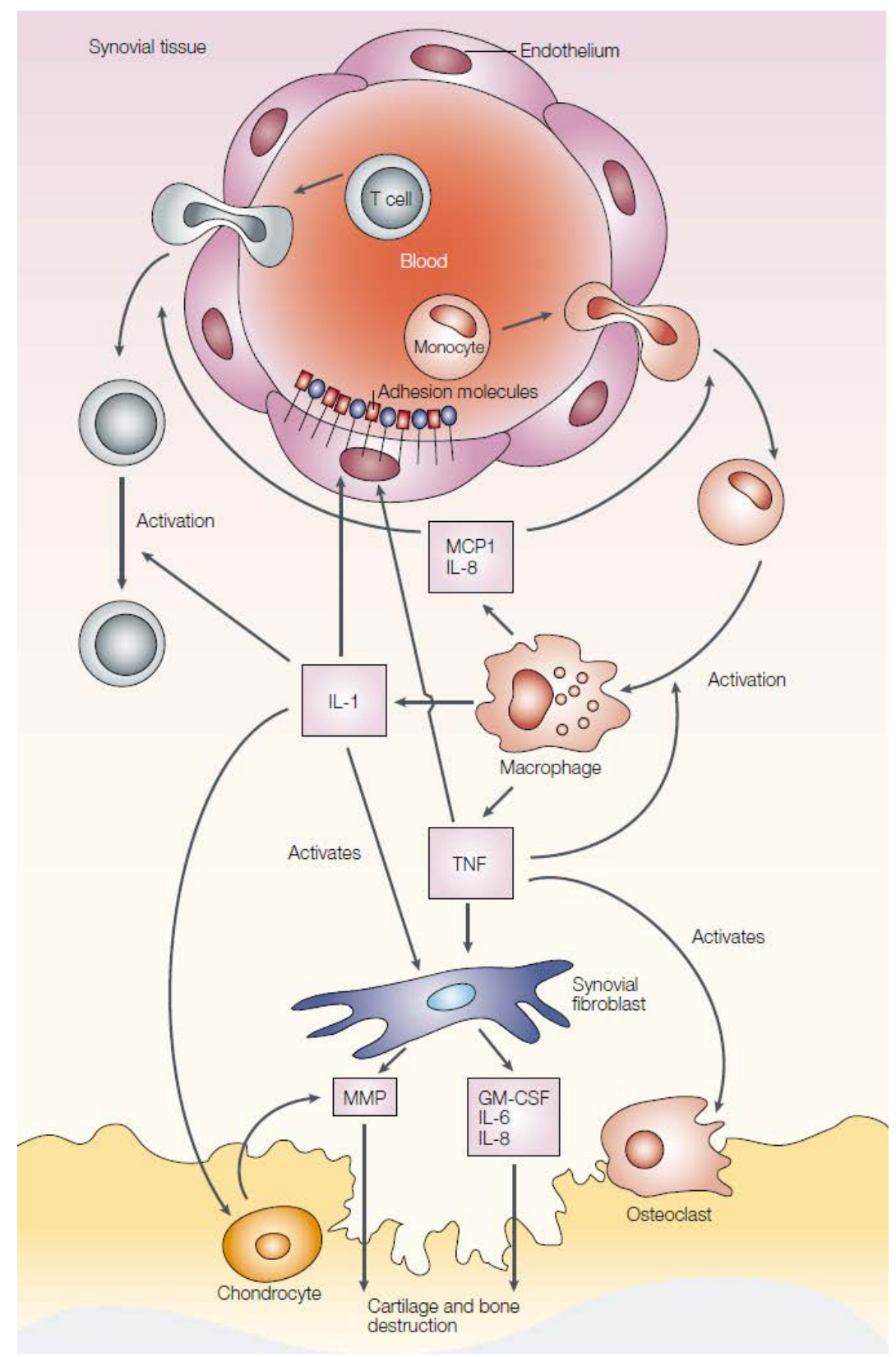

Fig. 10. Overview of the pathogenesis of rheumatoid arthritis.Monocytes are attracted to the rheumatoid arthritis (RA) joint, where they differentiate into macrophages and become activated. They secrete tumour-necrosis factor (TNF) and interleukin-1 (IL-1). TNF increases the expression of adhesion molecules on endothelial cells, which recruit more cells to the joint. Chemokines, such as monocyte chemotactic protein 1 (MCP1) and IL-8, are also secreted by macrophages and attract more cells into the joint. IL-1 and TNF induce synovial fibroblasts to express cytokines (such as IL-6), chemokines (such as IL-8), growth factors (such as granulocyte-macrophage colonystimulating factor; GM-CSF) and matrix metalloproteinases (MMPs), which contribute to cartilage and bone destruction. TNF contributes to osteoclast activation and differentiation. In addition, IL-1 mediates cartilage degradation directly by inducing the expression of MMPs by chondrocytes.Adapted with permission from [181]. 

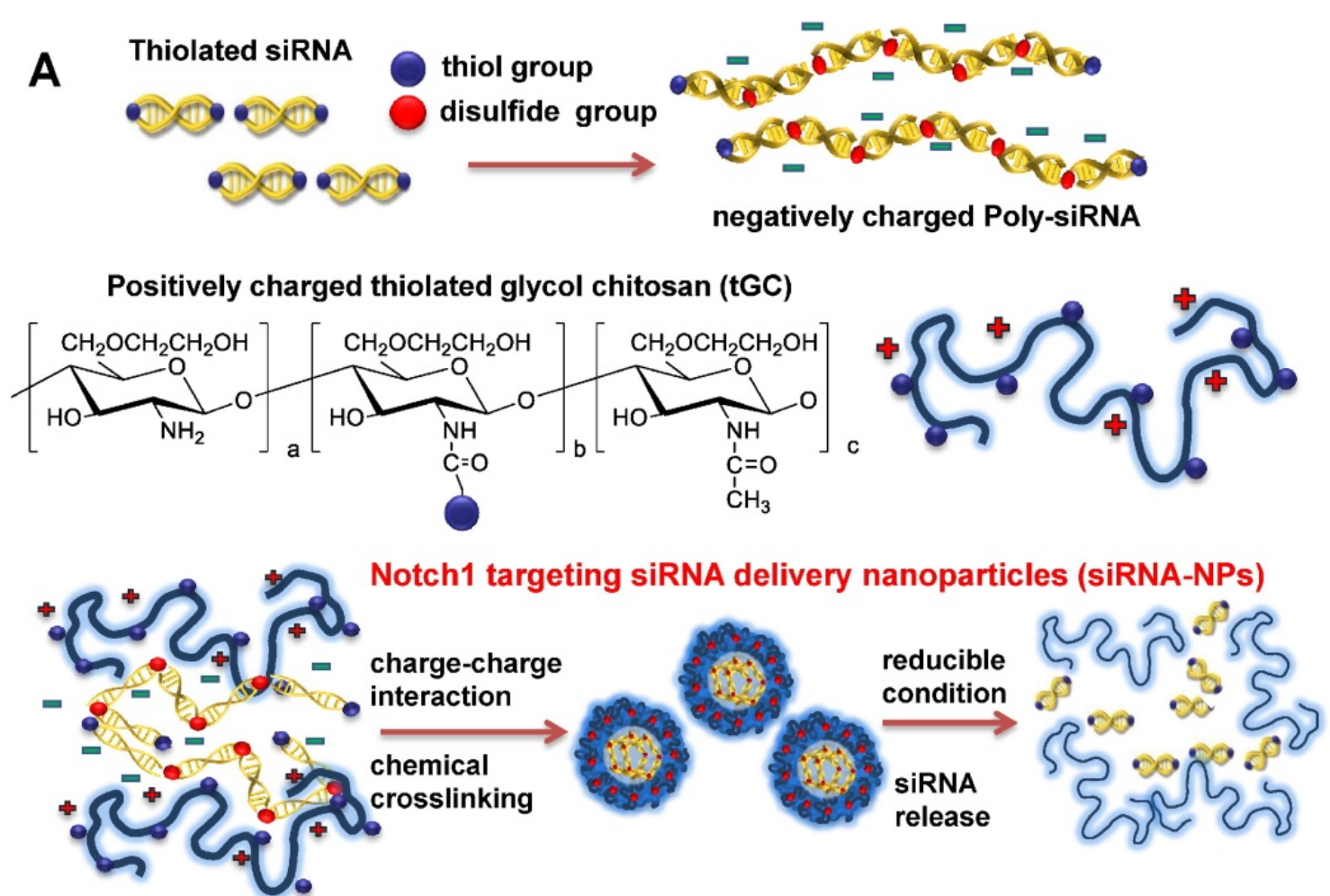

Rheumatoid arthritic joint

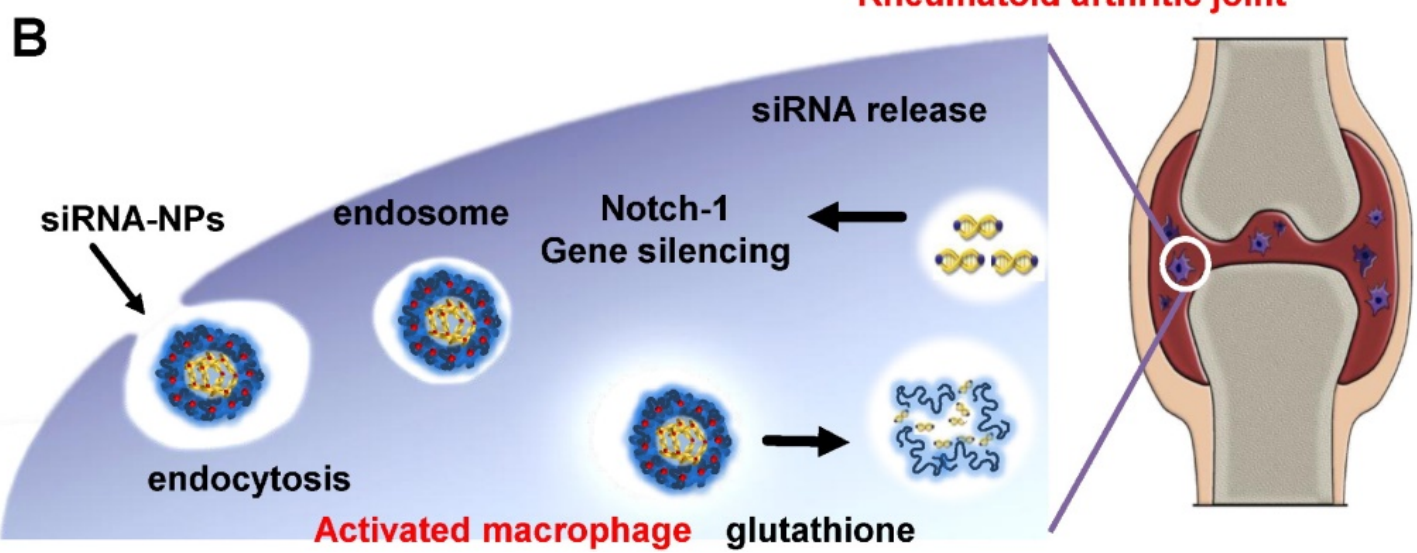

Fig. 11.Schematic diagram of Notch1 targeting siRNA delivery nanoparticles (siRNA-NPs). (A) The siRNA-NPs are prepared by encapsulating poly-siRNA into tGC nanoparticles. (B) The siRNA-NPs are taken by activated macrophage and the nanoparticles can deliver therapeutic Notch1-specific siRNA in RA treatment. Adapted with permission from [191]. 


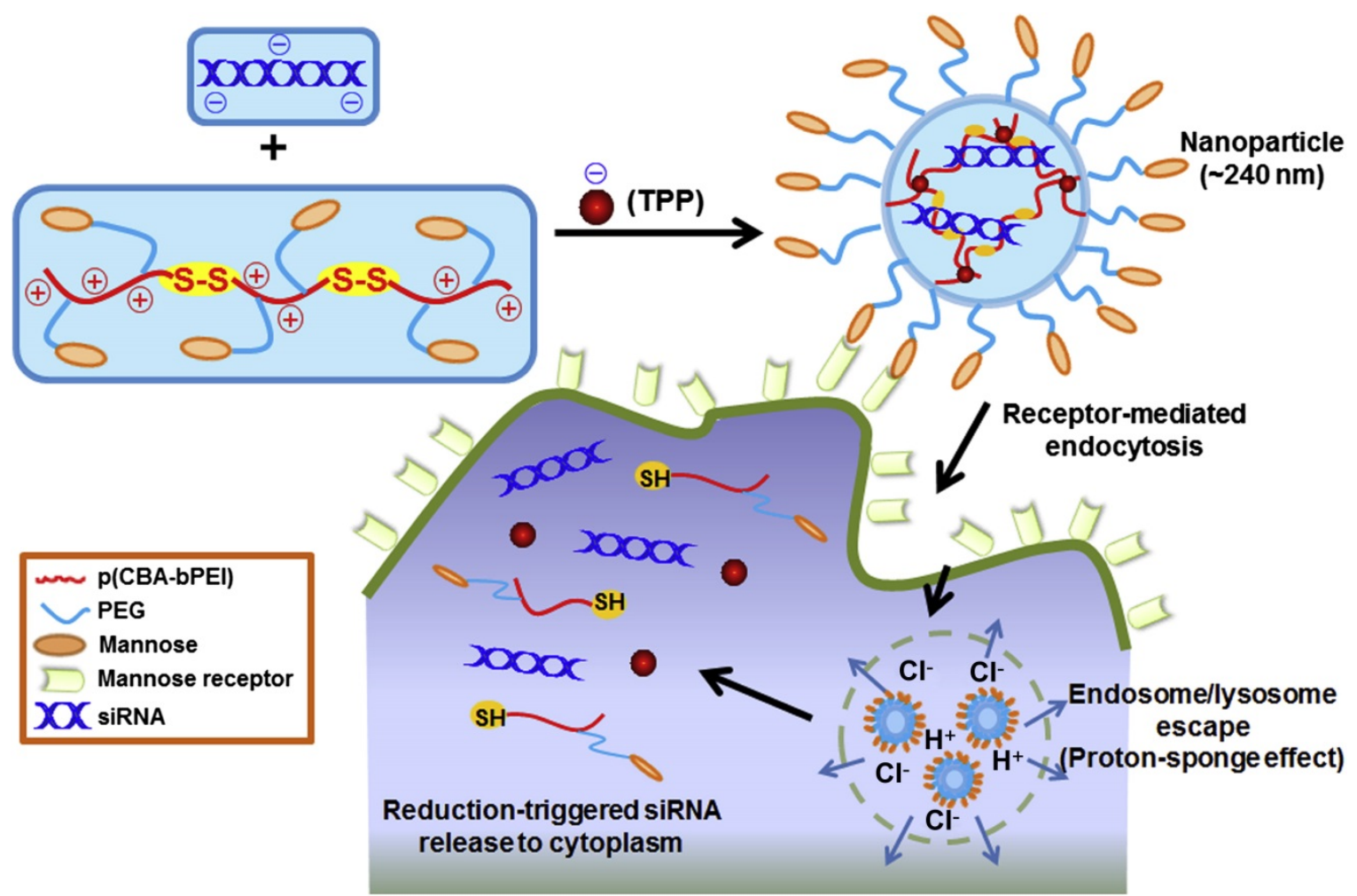

Fig. 12.Schematic illustration of TPP-PPM/siRNA nanoparticle (NP) formation, macrophagetargetingdeliveryand the release of siRNAs to the cytoplasm.Adapted with permission from [100]. 

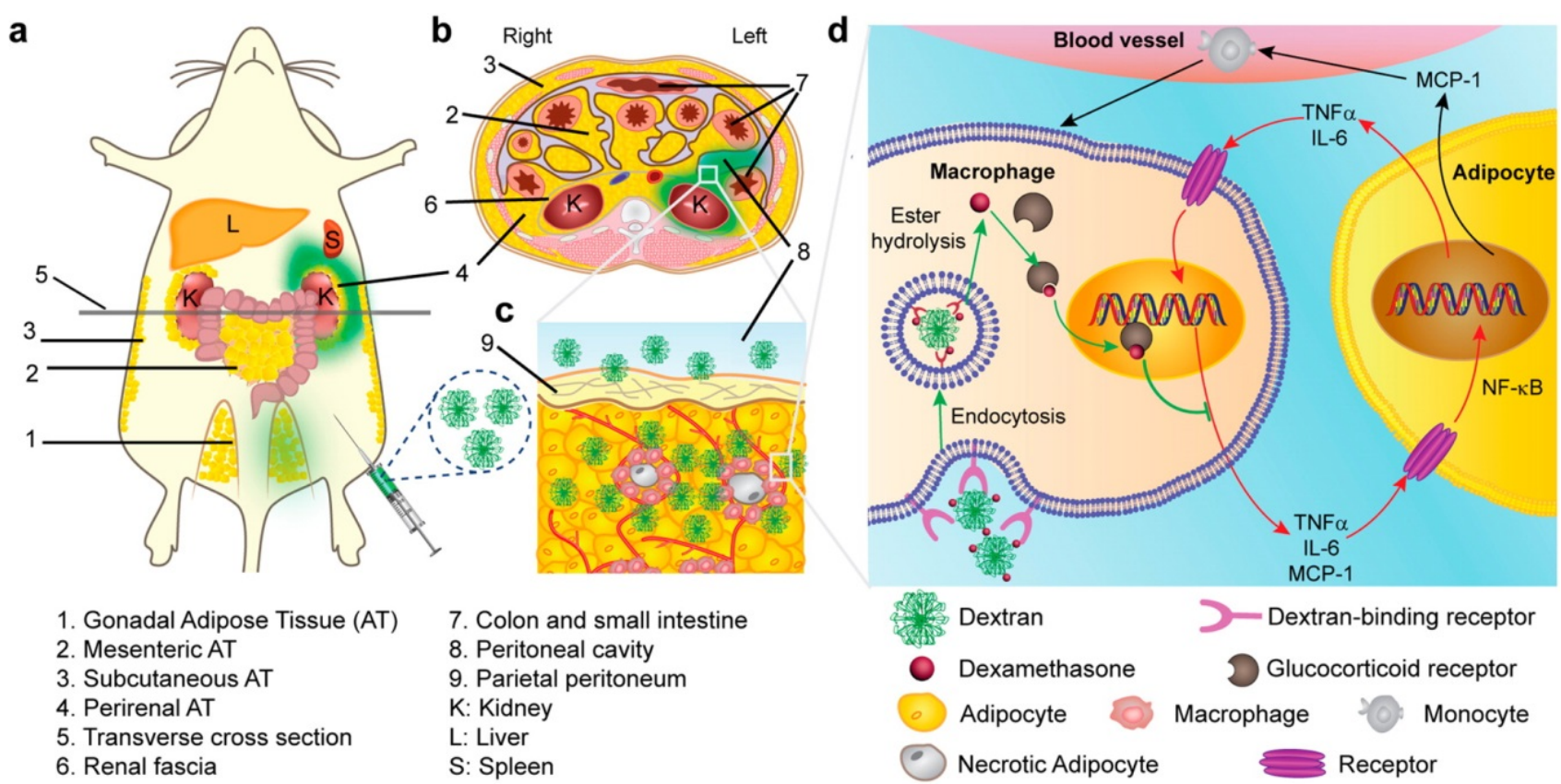

$\begin{array}{ll}\text { 1. Gonadal Adipose Tissue (AT) } & \text { 7. Colon and small intestine } \\ \text { 2. Mesenteric AT } & \text { 8. Peritoneal cavity } \\ \text { 3. Subcutaneous AT } & \text { 9. Parietal peritoneum } \\ \text { 4. Perirenal AT } & \text { K: Kidney } \\ \text { 5. Transverse cross section } & \text { L: Liver } \\ \text { 6. Renal fascia } & \text { S: Spleen }\end{array}$

Fig. 13.Proposed mechanism of dextran-dexamethasone conjugate accumulation in obese VAT, macrophage uptake, and uncoupling of the paracrine loop between M1 macrophages and adipocytes: (a) dextran conjugates (green color) accumulate in the left perirenal adipose tissue (AT) and left gonadal AT after intraperitoneal leftside injection in obese mouse. The anatomical depiction shows mice, which have one mesenteric, two perirenal, and two gonadal AT depots. (b) Transverse cross section of mouse abdomen showing green dextran solution location after administration to the peritoneal cavity. (c) Rapid association of dextran conjugate with M1 macrophages in inflamed AT is enabled by transport across the peritoneum to directly access interstitial cells. (d) Simplified summary of inhibition of paracrine loop between M1 macrophages and adipocytes with dextrandexamethasone conjugates. In the obese state, hypertrophied adipocytes produce MCP-1, which recruits monocytes, and local release of pro-inflammatory cytokines TNF $\alpha$ and IL-6 induces an M1 macrophage phenotype. M1 macrophages further release pro-inflammatory cytokines and chemokines including MCP-1, $\mathrm{TNF} \alpha$, and IL-6, which further enhance the pro-inflammatory gene expression of adipocytes through NF- $\mathrm{B}$ and further enhance adipocyte inflammation. Dextran conjugates are taken up by M1 macrophages through receptormediated endocytosis, and free dexamethasone is released within the cells after esterase hydrolysis. Dexamethasone then binds to the glucocorticoid receptor that inhibits the transcription of pro-inflammatory genes. Additional implicated cells (e.g., T cells) and altered metabolic pathways are not depicted.Adapted with permission from [111]. 


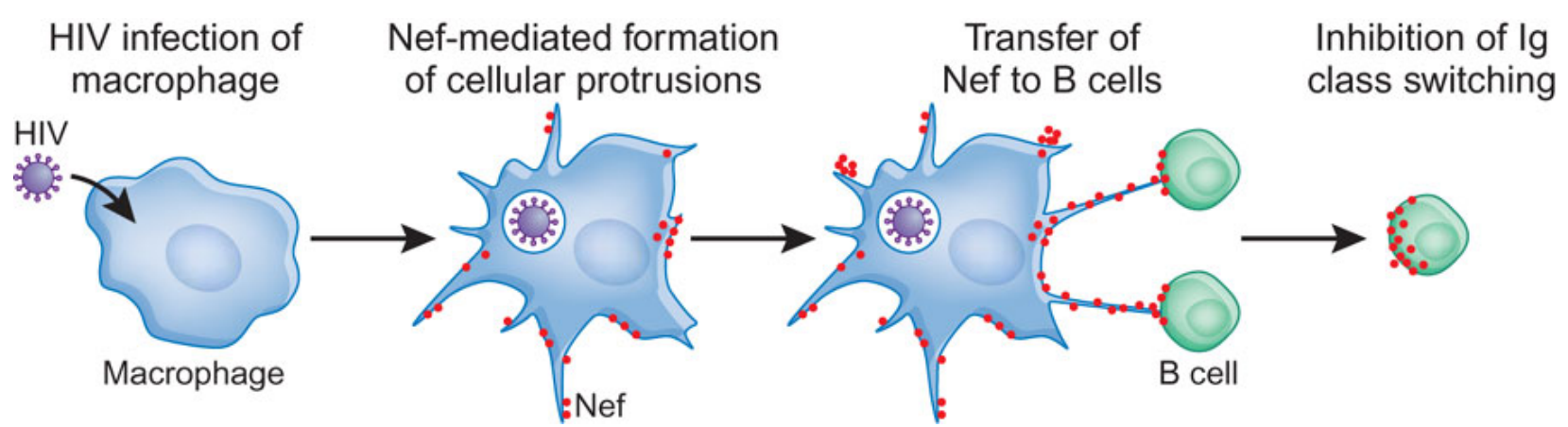

Fig. 14.HIV-1-infected macrophages shuttle Nef to B cells to impair follicular IgG2 and IgA responses. Adapted with permission from [215]. 


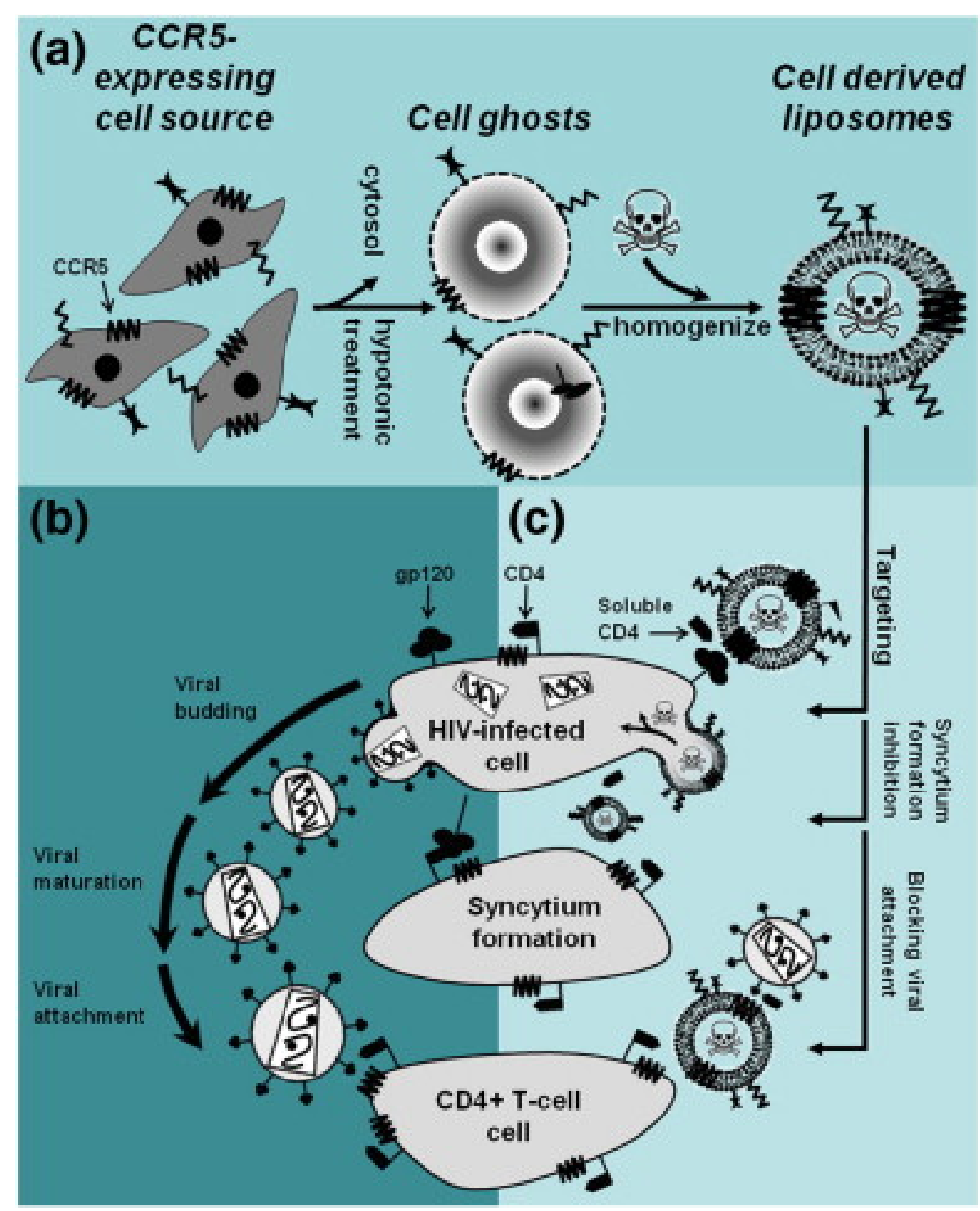

Fig. 15. The concept and rational of targeting HIV-infected cells by CCR5-conjuagted cell derived liposomes. (a) Cell-derived liposomes are prepared by homogenization and extrusion of ghost cells, which membranally express the HIV co-receptor CCR5. The source of the cells can be any autologous lineages that express CCR5 (naturally or exogenously). (b) Cell derived liposomes, which will be targeted against gp120-expressing cells using CCR5 as a targeting ligand, can interfere with all extracellular steps of viral pathogenesis; Such as, syncytium formation between infected cells and uninfected susceptible cells, viral budding from infected cells, viral maturation and attachment to susceptible cells. (c) The cell derived liposomes (when administered along with soluble CD4) are primarily intended to target, fuse with and deliver their cytotoxic content into gp120-expressing/HIV-infected cells. Accordingly, the same mechanism of gp120 binding may also prove efficient in preventing syncytium formation and inactivation of roaming virions by clustering.Adapted with permission from [221]. 